\title{
0 Crédito Imobiliário no Brasil e sua Relação com a Política Monetária
}

\author{
Mário Jorge Cardoso de Mendonça*
}

\begin{abstract}
Contents: 1. Introdução; 2. Aspectos Institucionais e Fatos Estilizados do Crédito Imobiliário no Brasil; 3. Estimando a Demanda por Crédito Imobiliário; 4. Demanda Crédito Imobiliário por Mudança de Regime; 5. Efeito de um Choque Monetário sobre o Setor Imobiliário; 6. Análise e Perspectivas Futuras; 7. Comentários Finais; A. Apêndice A.; B. Apêndice B. Descrição das Variáveis; C. Apêndice C. Gráfico das Variáveis do VAR; D. Apêndice D. Funções de Resposta Impulso; E. Apêndice E. Concessões de Crédito para Veículos Novos; F. Apêndice F. Endividamento das Famílias em Relação à Renda Acumulada em 12 Meses.

Keywords: Crédito Imobiliário, Causalidade Reversa, Modelo Markov Switching, VAR Estrutural, Gráficos Acíclicos Direcionados.

JEL Code: $\quad$ E32, R38.
\end{abstract}

Este estudo tem como objetivo analisar os determinantes da demanda por crédito imobiliário no Brasil assim como verificar o efeito dinâmico que um choque de política monetária sobre este. Com base no modelo com mudança de regime tipo Markov Switching, estimamos tal função de demanda usando dados mensais agregados de jan/03 a set/12. Os resultados acenam para o fato de que a demanda por hipoteca tem estado sujeita a ciclos de retração e expansão desde 2003. Um deles ligado à fase recessiva sendo que os outros dois estão ligados à fase expansiva do ciclo de crédito. 0 ciclo de expansão tem início ao final de 2005 é marcado pela alternância de dois regimes distintos. O regime que se concentra entre final de 2005 até inicio de 2009 foi impulsionado por fatores pró-mercado decorrentes das mudanças na legislação, crescimento da economia, aumento da renda real, etc. A partir de 2009, a situação se altera, passando a prevalecer um regime onde a expansão do crédito é mais motivada por ações de medidas anticíclicas adotadas pelo governo federal com intuito de mitigar os efeitos da crise de 2007-2008. A fase recessiva do ciclo de crédito ligada a um único regime que vai desde o início do período estudado até 2005 e retorna por volta de março de 2012 quando a série de concessões de crédito parece entrar em desaceleração. Aplica-se ainda o modelo vetor autorregressivo estrutural (SVAR) - structural vector autoregression - para avaliar o efeito de um choque de política monetária sobre a demanda por hipoteca. De acordo com os resultados, um choque

${ }^{*}$ Instituto de Pesquisa Econômica Aplicada (IPEA). Rio de Janeiro, RJ. E-mail: mario.mendonca@ipea.gov .br 
contracionista produz o efeito negativo sobre importantes variáveis ligadas ao setor imobiliário. Observa-se queda acentuada e contínua da demanda por financiamento, do preço dos imóveis, do produto da construção civil assim como aumento da inadimplência.

This study aims to analyze the determinants of demand for mortgages in Brazil as well as the effect of a restrictive monetary shock on real estate. Based on the Markov Switching model, we estimate the demand for mortgage using aggregate monthly data from Jan/03 to Sept 12 . The results show that this variable has been subject to cycles of contraction and expansion since 2003. The boom starts at the end of 2005 is marked by the alternation of two distinct regimes. The first one that concentrates between late 2005 until early 2009 seems ro be driven by factors pro-market resulting from changes in legislation, economic growth, rising in real income, etc. The situation changes at the beginning of 2009 when the condition of the demand for mortgage is mainly motivated by countercyclical measures adopted by the federal government with the aim of mitigating the effects of the world economic crisis of 2007-2008. The recessive phase of the credit cycle is linked to a single regime that extends until 2005 returning around March 2012 when the series of credit seems to slow down. We also applied the structural VAR model with the purpose of evaluating the effect of a monetary policy shock on the demand mortgage. According to the results, a contractionary shock produces a negative effect on real estate. We note a continuous and sharp decline in mortgage demand, price home, industrial output construction as well as rising on defaults.

\section{INTRODUÇÃO}

Além do crédito rural e das operações do BNDES, o financiamento habitacional ${ }^{1}$ se constituiu num outro pilar do crédito direcionado. No Brasil o governo participa ativamente do mercado imobiliário ${ }^{2}$ sendo seu principal agente de fomento através do direcionamento do crédito. Sabe-se que ao final de dez/12 as operações com recursos direcionados somaram uma participação $22,0 \%$ no total de crédito, o que mostra que a participação do crédito direcionado abocanha parte considerável dos recursos para empréstimos. Tomando o sistema financeiro como um todo, entre 2003 e 2010 a taxa de crescimento do estoque de crédito para habitação se situou em $17 \%$ a.a. contra a média geral, (que inclui outras atividades como indústria, crédito rural, comércio, pessoa física e outros serviços), de $12 \%$ a.a. No caso dos bancos públicos, a taxa média de expansão do crédito para habitação ficou em 19\% a.a.

Com a inflação controlada, a economia pode sentir os efeitos benéficos da estabilização. A queda da taxa de juros diminuiu o custo do financiamento, fator fundamental neste mercado, pois isso aumenta o valor do investimento imobiliário na medida em que o investimento em imóveis pode ser visto como

\footnotetext{
${ }^{1}$ Neste estudo usamos os termos crédito habitacional, crédito para hipoteca e crédito imobiliário para designar os empréstimos para financiamento de imóveis residenciais.

${ }^{2}$ Embora o crédito imobiliário possua sentido mais amplo se referindo às operações de financiamento não apenas de imóveis para habitação como também comerciais, neste estudo são usados os termos habitacional e imobiliário de indistintamente. Quando for o caso, a delimitação será feita no contexto.
} 
uma perpetuidade. Isto amplia a parcela deste tipo de investimento na composição do portfólio dos agentes. Também tendo em vista que normalmente uma transação imobiliária envolve financiamento de longo prazo, a estabilidade econômica permite maior segurança na predição do fluxo de caixa dos projetos. A queda da taxa de juros referencial induziu o aumento do saldo da caderneta de poupança ${ }^{3}$ disponibilizando mais recursos para o setor imobiliário tendo em vista que a rentabilidade da poupança é negativamente correlacionada ao nível da Selic. ${ }^{4}$ Também o aquecimento do mercado de trabalho, elevou a renda do trabalhador, facilitando a este o acesso ao mercado imobiliário. Além disso, as mudanças na legislação no setor imobiliário garantiram maior segurança não apenas ao emprestador como também aos mutuários.

Muito embora o governo participe ativamente do mercado de crédito imobiliário, podemos admitir que os fundamentos do próprio mercado imobiliário tenham contribuído fortemente para sua expansão, sobretudo a partir das reformas institucionais que aconteceram em 2004. No entanto, devemos estar atento igualmente ao fato de que os mesmos fundamentos já não possam mais explicar tão contundentemente a evolução do crédito no setor imobiliário. Esta hipótese deriva da apreensão de que o aprofundamento das medidas do governo orientadas para incentivar o setor, intensificadas a partir de 2008, têm induzido os agentes a orientar suas decisões com base menos nos fundamentos de mercado e mais por fatores outros tal como, por exemplo, movimento especulativo induzido por uma expansão exagerada do crédito.

Talvez seja por isso que concomitantemente a expansão do crédito que houve de janeiro de 2008 a outubro de 2012, ocorreu no preço de venda dos imóveis no Rio de Janeiro e em São Paulo ${ }^{5}$ variação de, respectivamente, $188 \%$ e $154 \%,{ }^{6}$ Tomando apenas o período de ago/10 a out/12, a variação do preço do imóvel no Rio de Janeiro foi $73,76 \%$ enquanto em São Paulo a variação ficou em 58,31\%. ${ }^{7}$ A possibilidade de que a demanda por crédito imobiliário para o período mais recente esteja menos relacionada aos fundamentos leva a preocupação de que cedo ou tarde o equilíbrio deverá se estabelecer com consequências possivelmente adversas tais como o aumento na inadimplência, queda no preço dos imóveis, perda de capital, etc.

Tendo em vista os comentários feitos até aqui, este estudo tem dois objetivos principais: analisar os determinantes da demanda por crédito imobiliário no Brasil assim como investigar que efeito um choque de política monetária terá esta variável. Assim sendo, este estudo está estruturado da seguinte forma. Na Seção dois, fazemos um resumo das principais mudanças institucionais ocorridas no setor imobiliário setor a partir de 2000. Na Seção três, introduzimos o modelo para a função demanda por crédito imobiliário visando detectar se existe causalidade reversa entre as concessões de crédito habitacional e preço dos imóveis. Assim, como faz todo o sentido afirmar que o preço do imóvel é um dos fatores que determinam a demanda por crédito habitacional também cabe responder se a expansão do crédito tem impacto sobre o preço dos imóveis. Tendo em vista que durante o período analisado aconteceram mudanças importantes não somente do ponto de vista institucional no mercado imobiliário como de outros, na Seção quatro, com base modelo com mudança de regime tipo Markov Switching a função de demanda por hipoteca. O emprego do modelo de mudança de regime nos permite

\footnotetext{
${ }^{3}$ Para cada real recebido para depósito em caderneta de poupança, os bancos devem direcionar 65 centavos para crédito imobiliário, $80 \%$ desse valor em crédito do âmbito do Sistema Financeiro de Habitação (SFH) cuja taxa é limitada em $12 \%$ a.a. mais TR (taxa referencial) e $20 \%$ em créditos a taxa de juros livremente fixadas pelas instituições credoras.

${ }^{4}$ Isso ocorre pelo comportamento quase fixo da Selic e pelo fato de que a rentabilidade dos fundos de renda fixa e dos CDBs ser altamente correlacionada com a Selic. A partir de 04 de maio de 2012, a regra de remuneração da poupança mudou. Até então a poupança rendia $6 \%$ a.a. mais a taxa referencial (TR), a partir dessa data a nova lei estabelece que sempre que a taxa básica de juros, a Selic, estiver em $8,5 \%$ ao ano ou abaixo desse patamar, o rendimento da poupança é $70 \%$ da Selic mais a TR. Quando a Selic for superior a 8,5\%, vale a regra antiga de reajuste pela TR mais 0,5\%. Atualmente, a Selic está em $8 \%$ ao ano.

${ }^{5}$ Usamos aqui dados do Fipezap. Não existem dados referentes a outras capitais no mesmo período.

${ }^{6}$ O IBOVESPA variou no mesmo período em apenas $-3,4 \%$ enquanto o CDI apresentou rendimento de $60,73 \%$. A taxa de inflação medida pelo IPCA no período foi de $29,4 \%$.

${ }^{7}$ Incluindo outras capitais (Brasília, Recife, Salvador Belo Horizonte e Fortaleza), a variação de ficou em 53,54\%.
} 
conhecer como a importância dos fatores determinantes da demanda por crédito sofreu alteração ao longo do tempo. A Seção cinco tem como propósito avaliar o efeito de um choque de política monetária sobre a demanda crédito imobiliário por meio de um modelo VAR estrutural. Por fim, os comentários finais são apresentados na Seção seis.

\section{ASPECTOS INSTITUCIONAIS E FATOS ESTILIZADOS DO CRÉDITO IMOBILIÁRIO NO BRASIL}

Tal como foi dito na introdução deste estudo, muitos são os motivos que podem ser apontados para explicar o crescimento do setor imobiliário presenciado nos últimos anos, sobretudo a partir de meados de 2005. O Gráfico 1 apresenta a série de concessões de crédito imobiliário ${ }^{8}$ desde 2003 . Conforme pode ser visto, a série mostra um salto ou mudança estrutural a partir de meados de 2005 . Mudanças na legislação no que concerne ao crédito imobiliário e da construção civil, a estabilidade de preços, a queda na taxa de juros, a expansão do crédito direcionado, a expectativa futura de valorização dos preços dos imóveis após um período longo de estagnação, programas de obras públicas e os programas de incentivo para aquisição da casa própria entre a população de baixa renda são as explicações mais recorrentes para este fenômeno. Na verdade, esta quebra de regime entre 2004 e 2005 é observada também para outras modalidades de crédito embora cada qual tenha suas especificidades.

Gráfico 1 - Concessões de Financiamentos Imobiliários

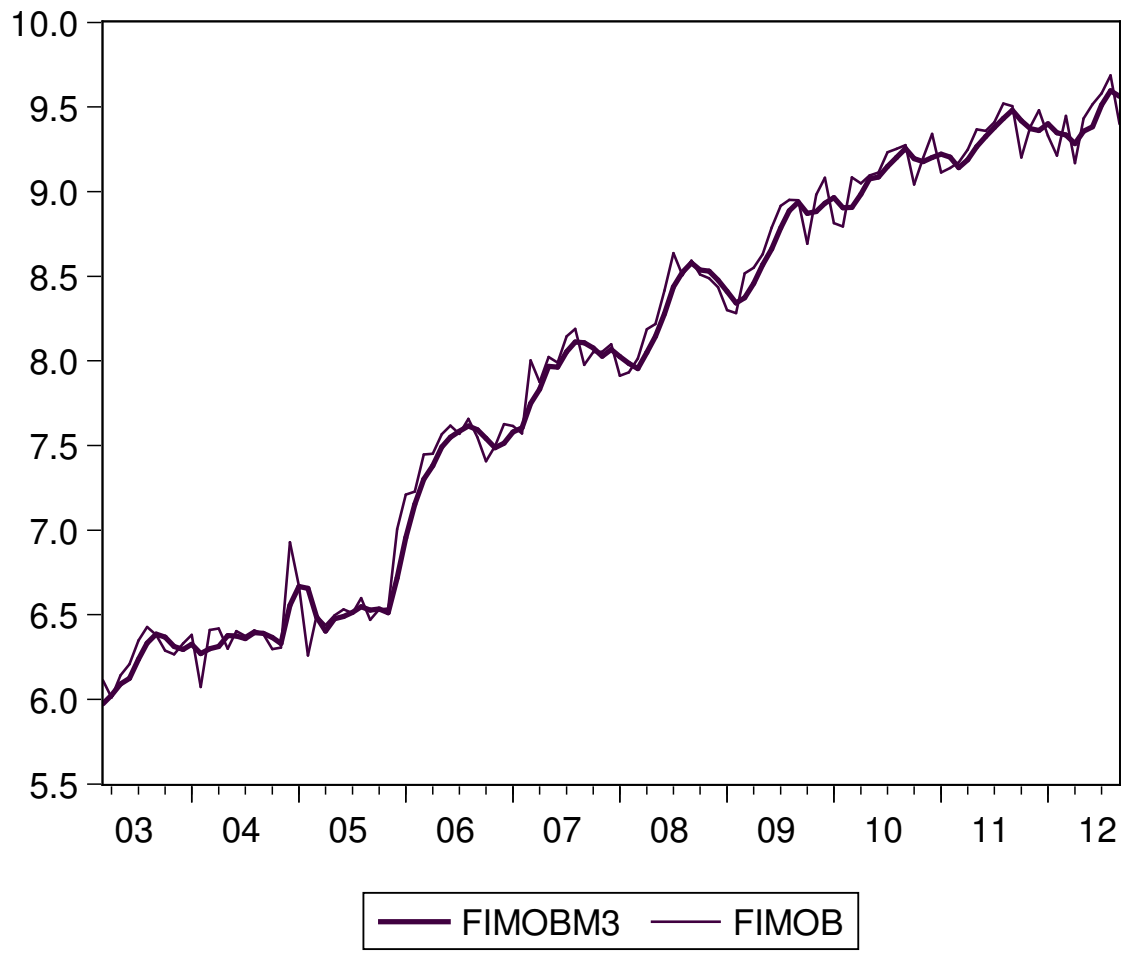

\footnotetext{
${ }^{8}$ Em logaritmo. Variável FIMOB: fluxo de financiamentos imobiliários, FIMOBM3: média móvel de três períodos da variável.
} 
Um ponto sumamente importante se refere às mudanças institucionais ocorridas no âmbito da legislação que tornaram o investimento no setor imobiliário bem mais seguro para todos os agentes envolvidos na compra de imóvel. Entre as alterações mais significativas no âmbito institucional, destacam-se as seguintes. A medida provisória no 2.221 ao final de 2001 cria a figura jurídica do patrimônio de afetação que diferencia os recursos captados para o financiamento da obra do patrimônio da incorporadora, reduzindo o risco para o comprador de imóvel na planta e para quem faz o financiamento da obra. A medida provisória no 2.223 editada em set/04 criou dois novos títulos, as Letras de Crédito Imobiliários (LCI) e as Cédulas de Crédito Imobiliário (CCI) que ampliaram a captação de recursos pelos agentes de financeiros responsáveis pela concessão de crédito imobiliário.

Outro marco na mudança na legislação no âmbito do $\mathrm{SFI}^{9}$ foi a introdução da Lei no 10.931 de agosto de 2004 que consolidou o instituto da alienação fiduciária do bem imóvel ${ }^{10}$ e que também indica que o valor incontroverso deve continuar a ser pago no tempo e modo contratados e a exigibilidade do valor controvertido pode ser suspensa mediante depósito do montante correspondente, no tempo e modo contratados. ${ }^{11}$ A alienação fiduciária ao manter a propriedade do bem financiado em nome da instituição financeira, garante maior segurança jurídica ao crédito imobiliário. A mesma lei criou um novo tipo de empresa: a companhia securitizadora imobiliária organizada por sociedade por ações. O objeto social deste tipo de empresa está na aquisição de créditos imobiliários originados das instituições financeiras que serão transformados em valores mobiliários sob a denominação de Certificados Recebíveis Imobiliários (CRI).

No entanto, como assinala Araújo (2012), até a eclosão da crise financeira de 2008-2009, a expansão geral do crédito no Brasil foi liderada pelos bancos privados ${ }^{12}$ sendo que a partir de 2008 a situação se inverteu. Muito embora no Brasil o governo sempre tenha estado à frente do credito imobiliário, sabe-se que a partir de 2008 houve um aprofundamento da expansão do crédito para este setor. Considerando o SBPE, ${ }^{13}$ de janeiro de 2008 a outubro de 2012 ocorreu um vigoroso aumento do saldo de crédito imobiliário, que mostrou variação de $328 \%$ em termos reais enquanto que entre agosto 2010 a outubro de 2012 a variação foi de $86,36 \%$.

Evidentemente, as políticas públicas do governo específicas para este setor também ajudaram a dar mais ímpeto ao mercado imobiliário. Tais ações públicas englobam um conjunto de medidas tais como aquelas que têm como objetivo facilitar o acesso à casa própria a grupos específicos da população, sobretudo aos grupos pertencentes ao extrato de baixa renda. ${ }^{14}$ Não obstante, houve redirecionamento dos recursos da poupança para o sistema de financiamento da casa própria. A medida, aprovada pelo Conselho Monetário Nacional, incrementou em R\$ 1,6 bilhão os recursos para o setor. Por fim, implementação de um programa de obras públicas que tem como propósito modernizar e dinamizar algumas cidades para atender os eventos mundiais com a Copa do Mundo em 2014, e as Olimpíadas no Rio de Janeiro em 2016, vem contribuindo para a valorização dos imóveis.

\section{ESTIMANDO A DEMANDA POR CRÉDITO IMOBILIÁRIO}

Na seção anterior vimos que o mercado imobiliário experimentou várias mudanças institucionais importantes até meados da década de 2000. Estas mudanças, dentre as quais se destacam o instituto

\footnotetext{
${ }^{9}$ Sistema Financeiro Imobiliário.

${ }^{10} \mathrm{Na}$ verdade, o instituto da alienação fiduciária de imóveis foi introduzido pela Lei no 9514 que criou também o SFI.

${ }^{11}$ Para uma resenha detalhada acerca das mudanças institucionais ocorridas desde a criação do Sistema Financeiro de Habitação em 1964, ver Martins et alii (2008).

${ }^{12}$ De propriedade privada ou estrangeira.

${ }^{13}$ Sistema Brasileiro de Poupança e Empréstimo cuja principal fonte de recursos é a caderneta de poupança.

${ }^{14} \mathrm{O}$ projeto Minha Casa Minha Vida tem como foco as famílias que possuem renda de zero a três salários mínimos.
} 
da alienação fiduciária ${ }^{15}$ e a figura do patrimônio de afetação ajudaram sem sombra de dúvida a gerar um ambiente favorável à expansão do mercado imobiliário. Conforme pode ser visto no Apêndice A, o volume de concessões de crédito habitacional apresenta um salto entre 2005 e 2006 que adquire caráter permanente que muito provavelmente se deveu em grande parte às inovações introduzidas na legislação.

Este estudo parte da hipótese que, em princípio, os agentes demandam empréstimos hipotecários pelo fato que eles não possuem riqueza suficiente para financiarem seus imóveis. Portanto, os compradores tomam emprestado do sistema bancário quantidade máxima de empréstimos estes estão dispostos a oferecer. Artle e Varaiya (1978) fornecem uma análise teórica acerca da decisão de comprar uma casa em um cenário de ciclo de vida. Isso proporciona um ponto de partida para a especificação de uma equação de demanda por empréstimos hipotecários. Os autores mostraram que o preço do imóvel é o determinante mais importante para explicar o valor do empréstimo.

No campo empírico, grande parte da pesquisa sobre demanda de financiamento imobiliário usa como variáveis explicativas aquelas ligadas às características específicas do demandante além de variáveis de preço. Dhillon et alii (1987) exploram uma base de dados de hipotecas entre 1983 e 1984 obtida junto aos bancos de Luisiania constatando que variáveis ligadas a preços (preço do imóvel e taxa de financiamento) são variáveis fortemente significativas para explicar a demanda por hipoteca enquanto que caracteríticas individuais como, por exemplo, renda e idade são menos significativas.

Brueckner e Follain (1988) usando dados desagregados de 1995 obtidos junto a Associação Nacional de Corretores mostram que ligadas a preço como o nível da taxa fixa de financiamento e a diferencial entre esta e a taxa ajustada são os melhores preditores para explicar a demanda por hipoteca com taxa ajustadas. Também Nothaft e Wang (1991) obtém resultados similares. Jones et alii (1995) também procuram verificar que fatores estariam por trás para explicar a demanda por uma hipoteca. Este estudo tenta avançar na medida em que incorpora na discussão o lado da oferta no mercado de hipoteca com intuito de controlar uma suposta endogenia no custo de financiamento. De acordo com Jones et alii (1995) entre os principais determinantes da demanda por hipoteca estão o custo do financiamento, ${ }^{16}$ o preço do imóvel, a confiança do consumidor e a volatilidade da taxa de juros de curto prazo.

Com base no que foi dito, será estimada uma função demanda por hipoteca cujos determinantes são o preço do financiamento (SELIC) que será representada aqui pela taxa de juros básica da economia, o índice de preço do imóvel (PRIMOV) e pela renda real (RENDA), representada aqui pela renda do trabalho principal. É necessária ainda uma variável de escala, pois quanto maior o volume de negócios no mercado imobiliário maior deverá ser também o volume de concessão de crédito. Aqui será utilizado, o índice da produção industrial da construção civil (INDCC) para representar essa variável. Esta variável pode ser vista como uma proxy para representar a confiança no setor. Assim, consideramos que a função de demanda por financiamento imobiliário pode ser representada pela seguinte equação:

$$
F I M O B_{t}=\beta_{0}+\beta_{1} S E L I C_{t}+\beta_{2} P R I M O V_{t}+\beta_{3} R E N D A_{t}+\beta_{4} I N D C C_{t}+D 06+\varepsilon_{1 t}
$$

onde $F I M O B_{t}$ é a volume de concessões ${ }^{17}$ de financiamento imobiliário no período $t$. As outras variáveis foram definidas acima. Por teoria temos que $\beta_{1}$ tem sinal negativo, pois representa o custo

\footnotetext{
${ }^{15} \mathrm{~A}$ lei da alienação fiduciária não se restringiu apenas ao mercado imobiliário, mas também a outros mercados como, por exemplo, o de veículos. Assunção et alii (2012) mostra que houve mudanças estruturais no perfil do crédito para aquisição de veículos em decorrência da introdução da lei da alienação fiduciária como diminuição do spread, aumento dos empréstimos e do prazo de financiamento. No entanto, diferentemente deste último onde o colateral no caso o veículo se desvaloriza substancialmente logo após a venda e mantém esta tendência, o imóvel em geral tende a se valorizar ou pelo menos acompanhar a inflação. Assim, depreende-se que o efeito do instituto da alienação fiduciária tenha sido bem maior no mercado imobiliário que em outros mercados.

${ }^{16} \mathrm{O}$ custo de financiamento é representado pela taxa fixa de financiamento (FRM) e a diferença entre esta e a taxa ajustada (ARM).

${ }^{17} \mathrm{O}$ termo concessão se relaciona com o fluxo mensal de novas concessões de crédito.
} 
de financiamento enquanto que o sinal do coeficiente $\beta_{2}$ se presume pelo menos em princípio como sendo positivo. Por hipótese, quanto maior o preço do imóvel menor será capacidade do adquirente de fazer a compra à vista e, portanto maior o valor da hipoteca. Também, numa situação em que existe tendência de crescimento no preço dos imóveis os agentes podem obter várias vantagens decorrentes desse aumento.

Primeiro, podem tirar vantagem do efeito riqueza. Neste caso, usa-se o financiamento para compra do imóvel passando adiante por um preço maior, quitando o débito e obtendo lucro na operação. Em segundo lugar, como o imóvel financiado entra como colateral, o mutuário pode fazer um refinanciamento visando adquirir um imóvel mais caro (Jones et alii, 1995). Pode acontecer que o preço do imóvel seja guiado pelo movimento especulativo tal como ocorre num processo de formação de bolha especulativa. Tal movimento de alta no preço dos imóveis leva os agentes a acreditar que tal elevação se manterá indefinidamente. Esta alta do preço induzirá naturalmente ao aumento na demanda por hipoteca na medida em que o imóvel se torna mais atrativo como investimento. Portanto, pelos motivos alegados, espera-se que exista uma relação positiva entre o preço do imóvel e o volume de empréstimos.

Com relação às variáveis RENDA e INDCC, espera-se que ambas tenham sinal positivo. No caso da renda, temos que esta variável entra como representativa da capacidade de pagamento. Assim quanto maior a renda, maior a capacidade de obter empréstimo para o financiamento habitacional. No que se refere ao índice da construção civil, esta variável além de ser uma variável que tem como objetivo controlar a tendência ou escala ela é também supostamente capaz de controlar a confiança dos indivíduos no setor. Incluímos ainda uma variável dummy D06 visando controlar a quebra estrutural ocorrida na variável FIMOB entre meados de 2005.

Pode-se argumentar que a taxa de financiamento do imóvel não deveria ser representada pela taxa Selic e sim pela taxa realmente contratada, sendo que tal taxa seria derivada da interação entre a demanda e a oferta de financiamento habitacional. No entanto, deve-se ter em mente que o seguimento de crédito para habitação constitui um dos pilares do crédito direcionado onde o governo é quem basicamente arbitra a taxa de financiamento. ${ }^{18}$ No que se refere ao SFH, o governo fixa ou limita a taxa de financiamento ofertando recursos para concessão de empréstimos de modo a atender a demanda. Assim, a taxa de financiamento não obedece à lei da oferta e da procura. O governo determina a taxa e o volume de financiamento decorre dela. Portanto a identificação ocorre no sentido que o preço (taxa de financiamento) afeta a demanda, mas não o contrário. A curva de oferta é totalmente elástica. Uma das consequências do direcionamento do crédito em tal proporção é que não existe ou, pelo menos, é muito diminuída a questão da causalidade reversa no processo de interação entre a oferta e demanda por empréstimos habitacionais. Na verdade existe um seguimento do crédito imobiliário cuja taxa é "livremente" ${ }^{19}$ determinada pelas instituições financeiras. No entanto, mesmo este seguimento deriva seus recursos de cerca de $20 \%{ }^{20}$ dos depósitos feitos na caderneta de poupança cuja remuneração é também arbitrada pelo governo. ${ }^{21}$

A equação (1) postula que o preço do imóvel tem efeito sobre o financiamento, mas é questionável também seria razoável postular que o volume de financiamento pode afetar o preço? Com o objetivo de verificar a existência de causalidade reversa ou simultaneidade entre as variáveis FIMOB e PRIMOV temos que ter outra equação que determina o preço do imóvel. Será assumida a seguinte equação para formação do da variável PRIMOV

$$
P R I M O V_{y}=\alpha_{0}+\alpha_{1} S E L I C_{t}+\alpha_{2} F_{I M O B_{t}}+\alpha_{3} A L U G_{t}+\alpha_{4} V I N C C_{t}+\varepsilon_{2 t}
$$

\footnotetext{
${ }^{18}$ Ver nota de rodapé 4.

${ }^{19}$ Observa-se que as taxas de juros pré e pós cobradas neste seguimento mantém uma tendência próxima a taxa Selic.

${ }^{20} \mathrm{O}$ restante vai para o crédito habitacional direcionado.

${ }^{21}$ Neste estudo usamos as concessões de crédito para habitação que estão inseridas apenas dentro do âmbito do SFH.
} 
De acordo com a equação (2), o preço do imóvel é determinado pela taxa básica de juros SELIC, o volume de concessões de empréstimos para financiamento imobiliário, o índice do aluguel (ALUG) e pela taxa de variação do índice de custo geral da construção civil (VINCC). O imóvel deve ser visto com um investimento num ativo real, assim quanto maior a taxa de juros menor sua atratividade como investimento, pois o custo de oportunidade se torna maior. Assim, na equação (2) um aumento da SELIC deve ter impacto negativo sobre o preço do imóvel. Em relação ao aluguel, esta variável representa rendimento usufruído pelo proprietário do imóvel seja alugando para terceiros ou para uso próprio. Portanto, espera-se obter uma relação positiva entre as variáveis PRIMOV e ALUG. Com relação ao custo da construção, é sabido que as construtoras reajustam o preço das unidades habitacionais durante a obra com base neste índice. Tendo em vista o enorme volume de lançamentos imobiliários ocorridos a partir de 2005, é razoável admitir a influência deste índice na formação do preço dos imóveis.

\subsection{Descrição da base de dados}

Antes de passar aos resultados, é necessário tecer algumas considerações acerca das variáveis que são utilizadas neste estudo. Trabalha-se com informação para o período entre janeiro de 2003 e setembro de 2012. Em relação ao preço do imóvel, utiliza-se o Índice de Valores de Garantia de Imóveis Residenciais Financiados (IVG-R) ${ }^{22}$ calculado pelo Banco Central do Brasil. Sabe-se que existem grandes dificuldades para obter uma medida fidedigna tanto do ponto de vista teórico do prático (Gregory e Wood, 2003). Do ponto de vista teórico, o imóvel é um bem heterogêneo e, portanto isso cria dificuldade de se prever o preço de um imóvel com base em um outro. Do ponto de vista prático, existem igualmente sérios entraves para se obter os valores realmente transacionados no mercado.

O índice de imóveis anunciados Fipezap (Fipezap, 2011) emprega os anúncios de imóveis como fonte de informação tal como é feito em outros países. Uma desvantagem desse tipo de informação é que existe uma clara distância entre o preço ofertado e o preço de fato transacionado. Mas, podemos assumir a hipótese de que no médio e longo prazo a evolução dos dois preços tenha tendência semelhante, ${ }^{23}$ mesmo assim a série deste índice somente se inicia com abrangência nacional a partir de janeiro de 2010. Usamos neste estudo a taxa Selic como variável proxy da taxa de financiamento. ${ }^{24} \mathrm{~A}$ justificativa para isso é que a tendência da taxa de financiamento imobiliário tem acompanhado àquela da taxa Selic.

Para representar a variável aluguel usamos o índice do subitem aluguel dentro do item habitação do IPCA calculado pelo IBGE. Para denotar a renda, usamos duas variáveis proxies a taxa de desemprego aberta e a renda média do trabalho principal. Conforme pode ser visto no Apêndice A, este última possui forte estrutura sazonal e, portanto ela entra na regressão dessazonalizada. Também a série de preço de imóveis, possui estrutura sazonal e igualmente entra nas regressões dessazonalizada. Outro ponto importante é que a série das concessões de financiamento imobiliário é muito irregular. Neste

\footnotetext{
${ }^{22}$ Esse índice é calculado com dados de operações de financiamento imobiliário para pessoas físicas, em que a garantia é composta de alienação fiduciária de imóveis residenciais ou hipoteca imobiliária. O valor de avaliação de cada imóvel pelo banco no momento da concessão do crédito é a fonte primária de informação para construção do indicador (Evolução dos Valores de Imóveis Residenciais no Brasil, in Relatório de Estabilidade Financeira, março de 2013, Banco Central do Brasil).

${ }^{23}$ Outra solução seria usar os registros de cartórios de imóveis, contudo estes não dispõem de uma base de dados de fácil acesso. Mesmo assim, sabe-se que grande parte das escrituras não reflete os valores de transacionados de fato. Além disso, existe a possibilidade de construir um índice com base em dados das instituições financeiras responsáveis pelo financiamento imobiliário. Entretanto, isso ofereceria a perspectiva de uma parcela do mercado, pois muitas transações são feitas sem financiamento. Outro problema aqui é a defasagem do tempo, pois do momento em que a transação é realizada até a disponibilização dessa informação em formato de banco de dados podem transcorrer meses.

${ }^{24}$ No âmbito do Sistema Financeiro de Habitação (SFH) a taxa de financiamento possui um teto de $12 \%$ a.a. mais TR (taxa referencial) e no máximo $20 \%$ a.a. mais TR para concessão com base na taxa de juros livremente fixadas pelas instituições financeiras.
} 
caso, consideramos apropriado trabalhar com a média móvel de três períodos. A descrição de todas as variáveis usadas neste estudo aparece no Apêndice B.

\subsection{Identificação}

Conforme foi dito acima, especulasse a existência de causalidade reversa para a variável PRIMOV. Assim, é necessário usar um tratamento econométrico específico para tratar esse problema. A estratégia de identificação a ser empregada segue os seguintes passos. Primeiro, será estimada a função de demanda com base no método de variáveis instrumentais (IV). Em segundo lugar, serão aplicados os testes usuais de modo que seja certificado se de fato acontece problema de endogeneidade, e de modo que seja verificado se a regressão estimada não apresenta problemas de especificação tal como heteroscedasticidade, instrumentos fracos, sub-identificação, etc. Por fim, será uso do método de mínimos quadrados três estágios (3SLQ) para estimar o modelo de equações simultâneas (1-2).

Embora muitos estudos utilizem a abordagem GMM para estimação de modelos com problemas de endogeneidade, deve-se assinalar que esta metodologia não necessariamente é superior à estimação feita pelo método de variáveis instrumentais. Tal como ressalta Baum et alii (2007) numa excelente resenha acerca da aplicação dos métodos IV e GMM, a vantagem da abordagem GMM se dá sobretudo na presença de heteroscedasticidade. ${ }^{25}$ Ainda assim, tal vantagem em termos da propriedade de consistência do estimador GMM na presença de heteroscedasticidade pode ser ofuscada pelo custo de uma performance fraca para o caso de pequenas amostras. Deste modo, quando o problema de heteroscedasticidade não se faz presente, é preferível ainda o emprego do estimador de variáveis instrumentais. De modo a checar a existência de heteroscedasticidade na regressão, aplicamos neste estudo o uma versão específica do teste de Pagan e Hall (1983). ${ }^{26}$

Para que a aplicação do método IV seja adequada se faz necessário que os instrumentos sejam "bons instrumentos" no sentido de serem relevantes bem como válidos. No jargão econométrico isso significa que as variáveis usadas como instrumentos devam ser correlacionadas com os regressores endógenos e ao mesmo tempo ortogonais ao distúrbio da regressão. Neste sentido são mostrados na mesma tabela o teste de sub-identificação ${ }^{27}$ (Cragg e Donald, 1993, Kleibergen e Paap, 2006), ${ }^{28}$ o teste de sobre-identificação de Sargan-Hansen, ${ }^{29}$ além do teste de Stock-Yogo (Stock e Yogo, 2005) para verificar

\footnotetext{
${ }^{25}$ Embora na presença de heterocedasticidade a propriedade de consistência dos coeficientes estimados pelo método IV seja mantida, na estimação básica de variáveis instrumentais os erros padrão são inconsistentes e, portanto a inferência fica comprometida (Baum et alii, 2007).

${ }^{26}$ Este teste assume a hipótese nula de homocedasticidade.

${ }^{27}$ Para que uma equação seja identificada no modelo IV tanto a condição de ordem $(L>=K)$, onde $L$ é o número de variáveis instrumentais e $K$ o número de regressores, como a condição de posto devem ser preenchidas. Esta última assinala que $Q \times z=E\left(X^{\prime} Z\right)$ deve ser de posto completo, onde $X=(X 1, X 2)=$ (Endógenas, Exógenas) é a matriz de regressores, enquanto $Z=(Z 1, Z 2)=$ (Exclusos, Inclusos) é a matriz dos instrumentos, sendo $Z 2=X 2$. Quando isso não ocorre dizemos que o modelo é sub-identificado ou não identificado. Pode-se testar a condição de posto por meio do teste de Cragg e Donald (1993), cuja não rejeição da hipótese nula sugere que o modelo é sub-identificado.

${ }^{28} \mathrm{Na}$ presença de heteroscedasticidade e autocorrelação residual, a estatística de Cragg-Donald não mais permanece válida. Em tais circunstâncias, o teste de Kleibergen e Paap (2006) será usado como alternativa ao teste Cragg e Donald (1993) quando as circunstâncias assim exigirem.

${ }^{29} \mathrm{~A}$ independência do instrumento com relação ao distúrbio somente pode ser acessada se, e somente se, houver uma "abundância" de instrumentos, isto é, se a equação é sobre-identificada. Isto se dá quando a condição de ordem é satisfeita na desigualdade: o número de instrumentos excluídos é superior ao regressores endógenos. O teste de Sargan/Hansen é usado para testar a hipótese de sobre-identificação. Sob a hipótese nula os instrumentos são válidos, ou seja, não correlacionados com o distúrbio. Sob ainda esta hipótese, a estatística de teste tem distribuição qui-quadrado com $L$ - $K$ restrições sobre-identificadas.
} 
se os instrumentos são fracos. ${ }^{30}$ Usamos ainda o teste de Durbin-Wu-Hausman cuja hipótese nula é que o regressor é exógeno para verificar a endogeneidade da variável PRIMOV.

A pesquisa teórica econométrica mais recente sobre o método de variáveis intrumentais tem enfatizado muito a questão dos instrumentos fracos (Stock et alii, 2002, Moreira, 2003, Stock e Yogo, 2005). Ma (2002) aponta que o uso de instrumentos pode ser um sério problema nos estudos para a curva de Phillips Novo-Keynesiana. Quando os instrumentos são fracos, dois problemas sérios ocorrem na estimação por dois estágios (2SLS). O primeiro é a questão do viés. Embora o método 2SLS seja consistente, ${ }^{31}$ as estimativas são sempre viesadas para pequenas amostras. Segundo, quando os instrumentos são fracos, o erro padrão estimado se torna muito pequeno. Neste caso, o intervalo de confiança é não fidedigno, pois juntamente ao fato de que o ponto médio deste estimador ser viesado, temos que o intervalo de confiança se torna pequeno. Isso tudo faz com que o procedimento de teste de hipótese na estimação por 2SLS se fragilize no caso da ocorrência de instrumentos fracos. Como Staiger e Stock mostraram o problema de instrumentos fracos pode ocorrer mesmo se no primeiro estágio os testes são significativos nos níveis convencionais ( $5 \%$ ou $10 \%$ ) e para grandes amostras.

Vários testes são sugeridos na literatura para testar a hipótese de instrumentos fracos. Uma estatística comumente usada é o $\mathrm{R}^{2}$ do primeiro estágio com os instrumentos dito "inclusos" (Bound et alii, 1995). ${ }^{32}$ Contudo, quando existe mais de uma variável endógena na regressão, esse indicador pode não ser mais válido. Shea (1997) propôs uma estatística conhecida como " ${ }^{2}$ parcial" que capta a intercorrelação entre os instrumentos. Quando existe somente uma variável endógena, as duas medidas de $\mathrm{R}^{2}$ são equivalentes. Outra regra aplicada quando se tem apenas um regressor endógeno é checar o valor da estatística $F$ no primeiro estágio. Neste caso, um valor menor que 10 pode ser uma indicação que os instrumentos são fracos. Alternativamente Stock e Yogo (2005) sugerem um teste onde a hipótese nula é que o viés do estimador 2SLS seja menor que uma fração (digamos, 10\%) do estimador OLS. ${ }^{33}$ De acordo com Murray (2006) a mais recente abordagem em relação ao problema de teste de hipótese com instrumentos fracos e um único regressor endógeno é o "teste da razão de verossimilhança condicional", desenvolvido por Moreira (2003) e aperfeiçoado em Andrews e Moreira (2006) e Andrews e Stock (2005). O teste de Moreira (2003) supera as distorções encontradas nos testes convencionais ajustando os valores críticos do teste de hipótese de acordo com cada amostra, de modo que o intervalo de confiança corrigido gere um nível de significância correto. Assim, seus valores críticos "são condicionados" nos dados à disposição e não constante.

\subsection{Resultados}

A Tabela 1 apresenta os resultados obtidos a partir dos procedimentos econométricos apresentados na seção anterior. A coluna (1) estima a função de demanda por imóvel com base no método de mínimos quadrados ordinários (LS). Na coluna (2) estimamos a função demanda por financiamento como base no mesmo método. A diferenças entre essas as duas regressões reside no fato que na coluna (1) usamos o desemprego (DESP) como variável proxy da renda e não a renda do trabalho principal (RENDA) que aparece na coluna (2). O método LS que não corrige o problema de endogeineidade supostamente existente na variável PRIMOV tal como comentado na Seção 3, mas nos permite aplicar a estatística

\footnotetext{
${ }^{30}$ Instrumentos que explicam pouco a variação da variável explicativa endógena (fraca correlação entre $Z$ e $X$ ) são considerados instrumentos fracos. O teste de Stock-Yogo (Stock e Yogo, 2005) é calculado com base na estatística $F$ de Cragg e Donald (1993). Sob a hipótese nula o estimador é fracamente identificado no sentido de que o viés verificado é inaceitavelmente grande.

${ }^{31}$ De modo que quase certamente o valor médio do estimador 2SLS se aproxima do verdadeiro valor do parâmetro quando o tamanho da amostra convergir para o infinito.

${ }^{32}$ Alternativamente, isso também pode ser expresso como um teste $F$ da significância conjunta dos instrumentos exclusos Z1.

${ }^{33} \mathrm{O}$ teste de Stock-Yogo (Stock e Yogo, 2005) não mais recai na estatística $F$ que comumente aparece na prática econométrica, mas numa generalização da estatística de Cragg-Donald. Os valores críticos deste teste são obtidos a partir de uma distribuição não padrão.
} 
VIF $^{34}$ de modo a inferir por meio dele se existe problema de multicolinearidade na regressão (Judge et alii, 1982). De modo a corrigir o viés de causalidade reversa, a estimação da função é feita com base no método de variáveis instrumental (IV). Aqui a variável PRIMOV é instrumentalizada pelo índice do aluguel (ALUG) e a variação do índice de custo geral da construção (VINCC). Os resultados são mostrados na coluna (3). A estimação é refeita pelo método GMM cujo resultado aparece na coluna (4) com objetivo de corrigir o problema de autocorrelação apontado na regressão estimada pelo método IV. Por fim, as colunas (5) e (6) mostram, respectivamente, os resultados das funções de demanda e oferta por concessões de empréstimos imobiliários estimadas simultaneamente pelo método de informação completa 3SLS.

Em relação aos resultados obtidos, é oportuno mencionar que os sinais encontrados e níveis de significância estão em conformidade com o esperado e também em concordância com os resultados mencionados na literatura. Observa-se que as variáveis de preço como a taxa de financiamento SELIC e o índice de preço dos imóveis são fortemente significativas enquanto as variáveis representativas da renda RENDA e DESP são fracamente significativas. A demanda concessão de financiamento reage negativamente à taxa de financiamento e positivamente ao preço do imóvel enquanto a renda tem efeito positivo sobre a demanda. A variável dummy D06 parece captar a quebra estrutural ocorrida na variável FIMOB em meados de 2005. Nota-se ainda que quando a equação (1) foi estimada por IV, o efeito da variável RENDA aumentou enquanto que o efeito da variável PRIMOV diminuiu. Nas colunas (5) e (6) o sistema FIMOB e PRIMOV é estimado simultaneamente, os resultados aqui parecem indicar que de fato existe causalidade reversa no sentido de que o volume de hipotecas realimenta o preço dos imóveis.

Com base na regressão estimada para a demanda na coluna (3), aplicamos os testes de especificação descritos na seção anterior. O teste de Pagan-Hall não indicou a necessidade da aplicação de nenhum procedimento para correção de heteroscedasticidade. Entretanto, o teste de Cumby-Huizinga detectou problema de autocorrelação. De modo a corrigir isso, empregamos na coluna (4) o método GMM. este cujo resultado não difere basicamente do anterior $O$ teste de sub-identificação indica que a condição de ordem é preenchida. De acordo com as estatísticas para checar a capacidade dos instrumentos $\left(\mathrm{R}^{2}\right.$ parcial e o teste Stock-Yogo), o conjunto de instrumentos utilizados atende amplamente a condição de serem "bons instrumentos". Também o teste de Sargan/Hansen não rejeita a hipótese nula de que os instrumentos excluídos sejam não correlacionados com o resíduo. Assim sendo, os teste de especificação para checar a qualidade dos instrumentos indicam que as variáveis ALUG e VINCC atendem aos critérios de bons instrumentos. Por fim, o teste de Durbin-Wu-Hausman para checar problema de endogeneidade na variável INDPR rejeita a hipótese nula de que a variável PRIMOV seja exógena.

\section{DEMANDA CRÉDITO IMOBILIÁRIO POR MUDANÇA DE REGIME}

Conforme foi visto na seção anterior, o mercado imobiliário sofreu mudanças importantes decorrentes não apenas das mudanças na legislação mas também por força dos incentivos que o governo impôs ao setor. O efeito de tais mudanças no setor provavelmente deve ter conduzido à ocorrência de quebras estruturais na série de concessões de financiamentos. O objetivo desta seção é revisitar a função demanda por crédito imobiliário, novamente estimando esta função de modo a levar em consideração as supostas quebras estruturais por procedimento adequado. Um problema potencialmente importante quando existe intervenção ou mudança de regime é o fato de que as técnicas tradicionais não serem robustas à existência de quebras estruturais nos dados (Leybourne e Newbold, 2003, Noh e Kim, 2003, Cook, 2004). Tais quebras certamente ocorreram na concessão de crédito habitacional.

Este estudo se propõe a lidar com as referidas quebras estruturais por meio do emprego de um modelo que admite explicitamente a existência de vários regimes nos dados (denominado

\footnotetext{
${ }^{34}$ Variation Inflation Factor. Um valor abaixo de 5.00 indica a não ocorrência de problema de multicolinearidade.
} 
Table 1: Equação de Demanda de Crédito

\begin{tabular}{|c|c|c|c|c|c|c|}
\hline & LS & LS & $\mathrm{IV}^{*}$ & GMM* & \multicolumn{2}{|c|}{ 3SLS } \\
\hline & $\begin{array}{c}\text { FIMOB } \\
(1)\end{array}$ & $\begin{array}{c}\text { FIMOB } \\
(2)\end{array}$ & $\begin{array}{l}\text { FIMOB } \\
\text { (3) }\end{array}$ & $\begin{array}{c}\text { FIMOB } \\
(4)\end{array}$ & $\begin{array}{c}\text { FIMOB } \\
(5)\end{array}$ & $\begin{array}{c}\text { PRIMOV } \\
\text { (6) }\end{array}$ \\
\hline SELIC & $\begin{array}{l}-0.226 \\
(0.000)\end{array}$ & $\begin{array}{l}-0.203 \\
(0.000)\end{array}$ & $\begin{array}{l}-0.232 \\
(0.050)\end{array}$ & $\begin{array}{l}-0.212 \\
(0.088)\end{array}$ & $\begin{array}{l}-0.233 \\
(0.003)\end{array}$ & $\begin{array}{l}-0.108 \\
(0.001)\end{array}$ \\
\hline PRIMOV & $\begin{array}{c}2.031 \\
(0.000)\end{array}$ & $\begin{array}{c}2.205 \\
(0.015)\end{array}$ & $\begin{array}{c}2.099 \\
(0.000)\end{array}$ & $\begin{array}{c}2.091 \\
(0.000)\end{array}$ & $\begin{array}{c}2.110 \\
(0.000)\end{array}$ & \\
\hline RENDA & & $\begin{array}{l}0.084 \\
(0.005)\end{array}$ & $\begin{array}{c}0.209 \\
(0.056)\end{array}$ & $\begin{array}{c}0.214 \\
(0.064)\end{array}$ & $\begin{array}{c}0.180 \\
(0.076)\end{array}$ & \\
\hline DESP & $\begin{array}{l}-0.287 \\
(0.039)\end{array}$ & & & & & \\
\hline INDCC & $\begin{array}{c}0.457 \\
(0.000)\end{array}$ & $\begin{array}{c}0.552 \\
(0.000)\end{array}$ & $\begin{array}{c}0.671 \\
(0.000)\end{array}$ & $\begin{array}{c}0.680 \\
(0.000)\end{array}$ & $\begin{array}{c}0.675 \\
(0.000)\end{array}$ & \\
\hline ALUG & & & & & & $\begin{array}{c}0.165 \\
(0.000) \\
\end{array}$ \\
\hline VINCC & & & & & & $\begin{array}{c}0.120 \\
(0.000) \\
\end{array}$ \\
\hline FIMOB & & & & & & $\begin{array}{c}0.044 \\
(0.000) \\
\end{array}$ \\
\hline D06 & $\begin{array}{c}0.814 \\
(0.000)\end{array}$ & $\begin{array}{c}0.812 \\
(0.000)\end{array}$ & $\begin{array}{c}0.808 \\
(0.000)\end{array}$ & $\begin{array}{c}0.811 \\
(0.000)\end{array}$ & $\begin{array}{c}0.808 \\
(0.000)\end{array}$ & \\
\hline CTE & $\begin{array}{l}-3.703 \\
(0.003)\end{array}$ & $\begin{array}{l}-6.313 \\
(0.000)\end{array}$ & $\begin{array}{l}-7.168 \\
(0.000)\end{array}$ & $\begin{array}{l}-7.238 \\
(0.000)\end{array}$ & $\begin{array}{l}-7.188 \\
(0.000)\end{array}$ & $\begin{array}{c}0.233 \\
(0.000)\end{array}$ \\
\hline OBS & 117 & 117 & 117 & 117 & 117 & \\
\hline VIF & 7.19 & 5.17 & & & & \\
\hline $\begin{array}{l}\text { Teste de } \\
\text { Pagan-Hall }\end{array}$ & & & $\begin{array}{c}5.08 \\
(0.446)\end{array}$ & & & \\
\hline $\begin{array}{l}\text { Teste } \\
\text { Cumby- } \\
\text { Huizinga }\end{array}$ & & & $\begin{array}{c}46.11 \\
(0.000)\end{array}$ & & & \\
\hline $\begin{array}{l}\text { Teste de } \\
\text { sub-identificação }\end{array}$ & & & $\begin{array}{c}96.38 \\
(0.000) \\
\end{array}$ & $\begin{array}{l}34.35 \\
(0.000) \\
\end{array}$ & & \\
\hline $\begin{array}{l}\text { Teste de } \\
\text { Sargan/Hansen }\end{array}$ & & & $\begin{array}{c}0.361 \\
(0.548)\end{array}$ & $\begin{array}{c}2.04 \\
(0.605)\end{array}$ & & \\
\hline $\mathrm{R}^{2}$ Parcial & 97.33 & 98.42 & 98.93 & 98.93 & & \\
\hline $\begin{array}{l}\text { Teste de } \\
\text { Stock-Yogo }\end{array}$ & & & $\begin{array}{c}257.21 \\
19.93\end{array}$ & $\begin{array}{c}70.224 \\
19.93\end{array}$ & & \\
\hline $\begin{array}{l}\text { Teste de } \\
\text { Durbin-Wu-Hausman }\end{array}$ & & & $\begin{array}{l}5.390 \\
(0.022)\end{array}$ & & & \\
\hline
\end{tabular}

*Instrumentos excluídos: ALUG e VINCC. 
"Markov-Switching Models"), estimando as "probabilidades de transição" entre esses diferentes regimes endogenamente através do uso das chamadas "Cadeias de Markov" (Hamilton, 1989, 1993, Krolzig, 1997, Sims, 1999, 2001, 2005). Quando uma relação linear é submetida a uma quebra estrutural, ${ }^{35}$ parâmetros do modelo de regressão variam, resultando em não-linearidades e, via de regra, em violações das hipóteses convencionais de estacionariedade e normalidade dos erros. Como aponta Sims (2001), é um equívoco grave ignorar quaisquer fontes de não normalidade nos resíduos ao mesmo tempo em que se leva em conta mudanças nos parâmetros das variáveis. De fato, o teste de Pesaran e Taylor (1999) adaptado para estimação por variável instrumental por vezes denominado de teste de variável omitida, mas que provavelmente é melhor interpretado como sendo um teste para checar a ocorrência de não linearidades na forma funcional (pags. 124-125 Wooldridge, 2002), quando aplicado as regressões das colunas (3) e (4) da Tabela 1 rejeita a hipótese nula de não ocorrência de não-linearidades negligenciadas. ${ }^{36}$

Uma alternativa empregada para tratar quebras estruturais (e, portanto, as "mudanças de regime") exógenas se faz por meio da introdução de variáveis dummies em modelos lineares convencionais. Contudo, tal procedimento exige que se conheça antecipadamente o momento exato onde ocorreram as quebras, o que raramente é o caso na prática. E mesmo no caso improvável do pesquisador "acertar" a data exata da(s) quebra(s) relevante(s) bem como, respectivamente os períodos de duração das quebras, a mera introdução de dummies não resolve problemas relacionados a mudanças de regime na variância dos erros do modelo.

Modelos do tipo Markov-switching ${ }^{37}$ (MS) se caracterizam por assumir explicitamente a possibilidade de que, a cada momento do tempo, um número finito (e geralmente pequeno) de "regimes" ou "estados" podem ocorrer, sem que se saiba ao certo qual deles está sendo observado. A hipótese é que existem "probabilidades de transição" de um regime para o outro, probabilidades essas estimadas endogenamente pelos modelos $\mathrm{MS}^{38}$ Nada impede ainda que as mudanças de regime sejam aquelas do tipo "once-and-for-all-shifts" onde após a mudança, o novo regime permanece indefinidamente. Assim, a equação (1) quando reescrita na forma de um modelo Markov-Switching assume a seguinte especificação,

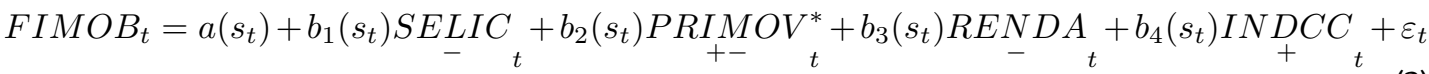

$$
\begin{aligned}
& \operatorname{com} \varepsilon_{t} \sim N\left(0, \sigma^{2}\left(s_{t}\right)\right)
\end{aligned}
$$

onde os sinas esperados para as variáveis explicativas aparecem sub-escrito abaixo delas. Note-se que, por hipótese, a "variável latente" $s_{t}$ é regida por um processo estocástico conhecido como uma cadeia de Markov ergódica e definido por uma matriz de probabilidades de transição cujos elementos são dados por:

\footnotetext{
${ }^{35} \mathrm{O}$ que pode ocorrer nos coeficientes das variáveis, no intercepto e também na variância dessa relação.

${ }^{36}$ Sob a hipótese nula não há não linearidades negligenciadas, os resíduos devem ser não correlacionados com os polinômios de baixa ordem dos valores projetados da variável dependente 0 teste estatístico (Wald ou distância GMM) para pequenas (estatística $F$ ) ou grandes amostras (Chi-2) com um número de graus de liberdade igual os número de termos polinomiais $[(F(1,110)=5.04-P$-value $=0.0268),($ Chi-sq $(1)=5.36, P$-value $=0.0206)]$.

${ }^{37}$ Mais tecnicamente, modelos MS se enquadram naquilo que Chib (1996) denomina de "hidden Markov chain models". Uma ampla variedade desses modelos é apresentada em Kim e Nelson (1999).

${ }^{38}$ Apenas para citar um exemplo intuitivo, parece razoável supor que uma economia em recessão se comporte de modo (ou tenha parâmetros) diferente(s) de uma economia em rápido crescimento. Nesse caso poder-se-ia pensar em dois "regimes", i.e. um "recessivo" e outro "de crescimento", com características bastante diferentes entre si e que se alternam de tempos em tempos, sem que se tenha certeza sobre qual está ocorrendo em cada período específico.
} 


$$
\begin{aligned}
& p_{i j}=\operatorname{Pr}\left(s_{t+1}=j \mid s_{t}=i\right), \sum_{j=1}^{k} p_{i j}=1 \vee i, j \in\{1, \cdots, k\} \\
& p_{i j} \geq 0 \text { para } i, j=1,2, \cdots, K
\end{aligned}
$$

Aqui, $p_{i j}$ representa a probabilidade de que, em $t+1$, a cadeia mude do regime $i$ para o regime $j$. A idéia, portanto, é que a probabilidade de ocorrência de um regime $s_{t}$ qualquer no presente depende apenas do regime que ocorreu no período anterior, i.e. de $s_{t-1}$. Com $k$ regimes existentes, as probabilidades de transição entre estados podem assim ser representadas pela matriz de transição de probabilidade $P$, com dimensão $(k \times k)$.

Conforme foi colocado ao longo da Seção 3, o modelo de demanda por hipoteca sugerido neste estudo supõe a existência de simultaneidade ou causalidade reversa no sentido de que as concessões de crédito também têm efeito sobre o preço dos imóveis realimentando o processo. De modo a corrigir este viés, instrumentalizamos a variável PRIMOV pelo mesmo conjunto de regressores que aparecem na equação (2) e estimamos com base no método LS. Este procedimento de dois passos está de acordo com o proposto por Kim (2004) para correção de viés de endogeneidade no modelo MS. A série projetada do índice de preço do imóvel é representada pela variável PRIMOV*.

Os parâmetros do modelo acima são estimados a partir da maximização da função de verossimilhança do modelo por meio do algoritmo EM (Dempster et alii, 1977) - uma técnica iterativa para modelos com variáveis omitidas e/ou não observadas. Pode ser mostrado que o valor da função verossimilhança relevante aumenta a cada iteração desse processo, o que garante que o resultado final seja suficientemente próximo do valor máximo da verossimilhança na vizinhança relevante. ${ }^{39}$ É necessário ter em mente, entretanto, que a função de verossimilhança de um modelo MS não possui máximo global (Hamilton, 1991, 1993, Koop, 2003). Felizmente, a utilização do algoritmo EM frequentemente leva a obtenção de um máximo local "razoável", com casos patológicos sendo relativamente raros (Hamilton, 1993).

\subsection{Resultados Econométricos}

Nesta subseção os resultados do modelo Markov-Switching (MS) são apresentados seguindo o procedimento descrito na seção anterior. Antes, porém, da análise dos resultados, deve-se tecer os seguintes comentários quanto à escolha do número de regimes. Na busca pelo melhor modelo, faz-se necessário observar o comportamento dos distintos critérios de escolha Akaike (AIC), Schwartz (SC) e Hannah-Quinn (HQ) e o valor verossimilhança $(L)$ frente os diferentes modelos competitivos permitindo mudanças no intercepto $(I)$, nos parâmetros das variáveis $(A)$ e nas variâncias $(H)$ em cada regime.

A Tabela 2 mostra os valores desses critérios assim como o teste de razão de verossimilhança (LR) que cuja hipótese nula é de linearidade, ${ }^{40}$ isto é, um modelo sem mudança de regime. Também nela se encontram os resultados dos testes para checar a normalidade (NORM) e o teste LM (ARCH) que procura detectar a presença de variância autoregressiva (ARCH). ${ }^{41}$ Tendo em vista a dimensão temporal da amostra, optou-se por testar os modelos concorrentes MS-IAH e MS-IH para dois e três regimes.

\footnotetext{
${ }^{39} \mathrm{Em}$ geral esse método se mostra robusto quando os valores iniciais são arbitrados de maneira arbitrária ou pouco eficiente.

${ }^{40} \mathrm{O}$ teste LR aqui possui distribuição não padrão, não podendo ser caracterizado analiticamente desde que as probabilidades de transição são não identificadas sob a hipótese de linearidade. Contudo é possível mostrar que esta distribuição pode ser aproximada, estando no intervalo entre duas qui-quadrado. Deduz-se disso que se essas distribuições rejeitarem a hipótese nula, o teste LR devera necessariamente fazê-lo. Contrariamente, se não houver rejeição da hipótese de linearidade por ambas então o mesmo devera acontecer para o teste LR. Em qualquer outra situação nada poderá ser dito (Davies, 1977, Hansen, 1992).

${ }^{41}$ Variância autoregressiva condicional heteroscedástica.
} 
Tendo em vista os resultados mostrados na Tabela 2, em nenhum caso o teste LR aceita a hipótese nula de linearidade frente ao modelo MS. Verifica-se também que todos os critérios de seleção de modelos indicam que o melhor modelo é o MS(3)-AIH. Além disso, para este modelo, com base nos testes de especificação não se rejeita as hipóteses nulas de normalidade e variância constante.

Table 2: Critérios para Seleção de Modelos Concorrentes e Testes de Especificação

\begin{tabular}{c|c|c|c|c|c|c|c}
\hline & LR Teste de Linearidade & AIC & HQ & SC & Log L & Norm & ARCH \\
\hline MS(2)-IAH & $\begin{array}{c}\text { Chi2(8)= } \\
231.10(0.000)\end{array}$ & -1.95 & -1.81 & -1.61 & 126.48 & $\begin{array}{c}\text { Chi2(2) } \\
1.73(0.74)\end{array}$ & $\begin{array}{c}\mathrm{F}(1,99) \\
23.8(0.00)^{*}\end{array}$ \\
\hline MS(2)-IH & $\begin{array}{c}\text { Chi2(4)= } \\
178.02(0.000)\end{array}$ & -1.56 & -1.46 & -1.32 & 99.94 & $\begin{array}{c}\text { Chi2(2) } \\
8.40(0.02)^{*}\end{array}$ & $\begin{array}{c}\mathrm{F}(1,103) \\
74.5(0.00)^{*}\end{array}$ \\
\hline MS(3)-IAH & $\begin{array}{c}\text { Chi2(17)= } \\
284.95(0.000)\end{array}$ & $-\mathbf{2 . 2 6}$ & $-\mathbf{2 . 0 4}$ & $-\mathbf{1 . 7 1}$ & $\mathbf{1 5 3 . 4 0}$ & $\begin{array}{c}\text { Chi2(2) } \\
3.74(0.15)\end{array}$ & $\begin{array}{c}\mathrm{F}(1,90) \\
0.33(0.56)\end{array}$ \\
\hline MS(3)-IH & $\begin{array}{c}\text { Chi2(8)= } \\
209.96(0.000)\end{array}$ & -1.77 & -1.63 & -1.44 & 115.91 & $\begin{array}{c}\text { Chi2(2) } \\
4.17(0.123)\end{array}$ & $\begin{array}{c}\mathrm{F}(1,99) \\
38.8(0.00)^{*}\end{array}$ \\
\hline
\end{tabular}

Antes da apresentação dos resultados, será feita uma tentativa de justificar por que o processo de escolha dos modelos concorrentes tem por base os modelos de dois e três regimes. Isto se justifica pelo fato do modelo MS ser muito parametrizado, ${ }^{42}$ tendo em vista, sobretudo, o tamanho da amostra. Portanto, considera-se estimar o modelo com um número pequeno de regimes. Observa-se que a introdução de um maior número de regimes conduziria a problemas no processo de otimização fazendo, por exemplo, com que a matriz de transição de probabilidade se torne não ergódica, o que viola uma das principais hipóteses do modelo. Tendo em vista ainda a dimensão temporal da série, parece pouco plausível que tenha ocorrido um número de regimes maior do que três durante este período. Mesmo que o número de regimes exceda a este, não considera-se que o modelo possa captá-lo de modo fidedigno devido ao tamanho da amostra.

Inicialmente de modo a ajudar na formulação de uma interpretação, podemos utilizar o modelo de dois regimes (MS(2)IAH) cuja Figura 1 apresenta o gráfico da cronologia dos regimes (notadamente da trajetória da probabilidade suavizada) ${ }^{43}$ para em seguida estender a nossa análise para o modelo de três regimes (MS(3)IAH). A comparação entre esses dois modelos nos permitirá tecer considerações interessantes provendo robustez da nossa análise. Conforme pode ser visto na Figura 1, observa-se que o regime finaliza sua primeira fase por volta de/05 recomeçando em mar/12. Neste ínterim aparece 0 regime 2. Cabe agora dar interpretação econômica a cada um dos regimes.

Com base na inspeção do terceiro gráfico da Figura 1, que confronta a série de concessão de crédito as séries de probabilidade suavizada, notamos claramente que o final do primeiro ciclo do estado 1 termina quando começa o ciclo de expansão do crédito. Este regime retorna por volta de março de 2012 quando a séria de concessões de crédito entra em desaceleração. Portanto, associamos este regime à fase recessiva do ciclo econômico do crédito habitacional. Contrapondo-se à fase recessiva do ciclo de crédito existe um período de aceleração do crédito que começa ao final de 2005. Interessante notar que ao contrário de outros mercados o crédito imobiliário pareceu não se ressentir dos efeitos da crise

\footnotetext{
${ }^{42}$ No caso, o número de parâmetros é 14 .

${ }^{43} \mathrm{~A}$ probabilidade suavizada (smoothed) considera informações de toda amostra, sendo definida da seguinte forma $\operatorname{Pr}\left[S_{t}=\right.$ $j \mid \Psi_{T}$ ], onde $\Psi_{T}$ é o conjunto de informação pleno até o instante $T$. A probabilidade filtrada (filtered) é uma inferência ótima no estado da variável no tempo $t$ considerando as informações até $t$, enquanto a probabilidade predita (predicted) considera a informação até $t-1$.
} 
mundial de 2008, pois a tendência de crescimento do crédito se manteve forte mesmo durante o período de crise.

Figure 1: Probabilidades Suavizadas - MS(2)IAH

REGIME 1

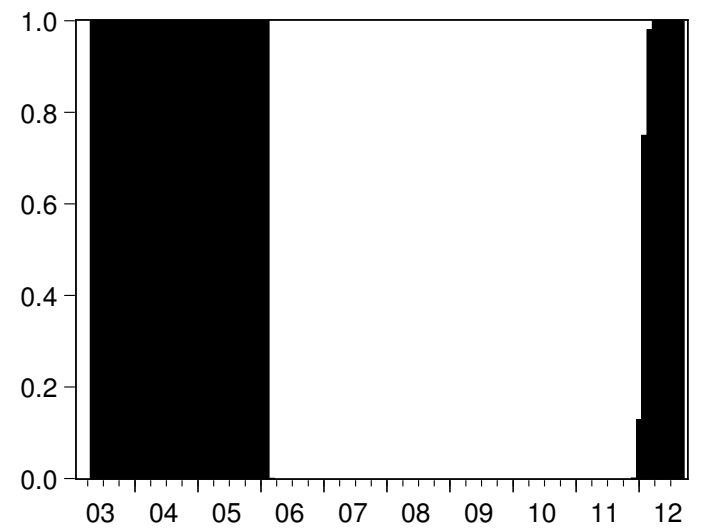

REGIME 2

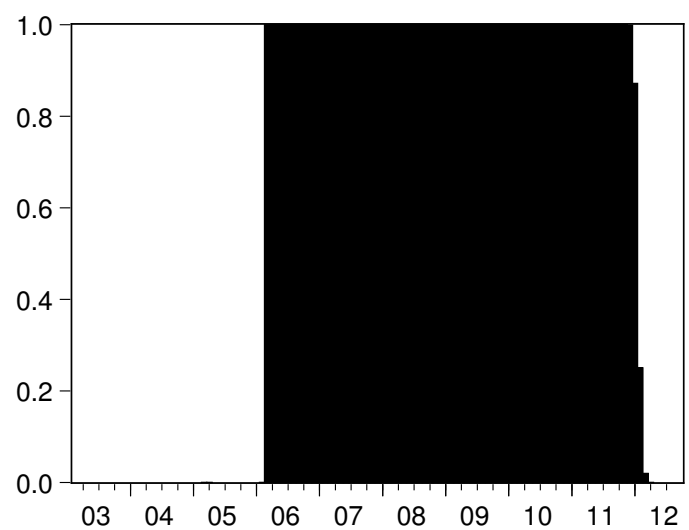

Para se ter uma ideia mais precisa do efeito da crise no mercado de crédito vejamos, por exemplo, o caso do mercado de veículo. No Apêndice E, aparece a série de concessões de crédito para aquisição de veículos. Pode-se ver claramente que de modo semelhante ao que acontece no crédito imobiliário, após um período de queda ou estagnação tem início um período de forte crescimento das concessões. A datação quanto ao início da fase expansiva do ciclo naturalmente depende em parte das características e do que acontece em cada mercado. No caso do mercado de veículo, verifica-se que existe uma queda acentuada quando da crise econômica mundial no início de 2008. As áreas sombreadas marcam os períodos de mudança no IPI que visava incentivar o aumento das vendas de veículos. Voltando à análise do crédito imobiliário, a questão que se coloca é por que diferentemente do crédito para de veículos além de outros segmentos, o mercado de crédito imobiliário não sofreu efeito da crise de 2008 ? Para entender por isso é necessário considerar o que acontece quando se introduz mais um regime no modelo. Isso aparece na Figura 2.

Table 3: Modelo MS(2)-AIH* Variável dependente: FIMOB

\begin{tabular}{l|c|c}
\hline & Regime 1 & Regime 2 \\
\hline CONST & $2.593(0.397)$ & $-17.743(0.001)$ \\
\hline SELIC & $0.017(0.821)$ & $-0.540(0.000)$ \\
\hline PRIMOV ${ }^{*}$ & $3.775(0.000)$ & $1.976(0.000)$ \\
\hline RENDA & $-1.833(0.000)$ & $1.915(0.020)$ \\
\hline INDCC & $-0.091(0.589)$ & $0.718(0.021)$ \\
\hline Desvio-Padrão & $0.053(0.000)$ & $0.089(0.000)$ \\
\hline \multicolumn{2}{|c|}{44} & 71 \\
\hline OBS & ${ }^{*} p$-valor entre parênteses. As variáveis tomadas no log.
\end{tabular}


Em princípio, podemos notar que a introdução de um terceiro regime não altera basicamente a datação do regime 1 aquele que associamos ao ciclo de retração do crédito imobiliário. Assim tal mudança se deve refletir no que acontece na fase expansiva do ciclo de crédito. Tal como no modelo de dois regimes, este ciclo tem início no final de 2005 sendo agora é marcado pela alternância ou prevalência de dois outros regimes (regimes 2 e 3). Nossa hipótese é que esses dois regimes são marcados por fundamentos econômicos distintos. Do final de 2005 até o inicio de 2009, o crescimento do crédito para habitação foi impulsionado por fatores pró-mercado decorrente de vários fatores como as mudanças na legislação mencionadas na Seção 2, crescimento da economia, aumento da renda real, etc. Este estado do crédito imobiliário se concentra no regime 3. Em 2009, a situação se altera, passando a prevalecer o regime 2 .

Figure 2: Probabilidades Suavizadas - MS(3)IAH

REGIME 1

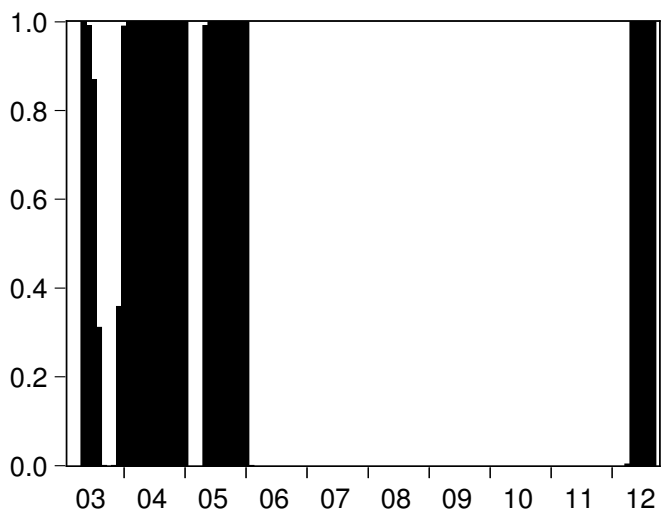

REGIME 2

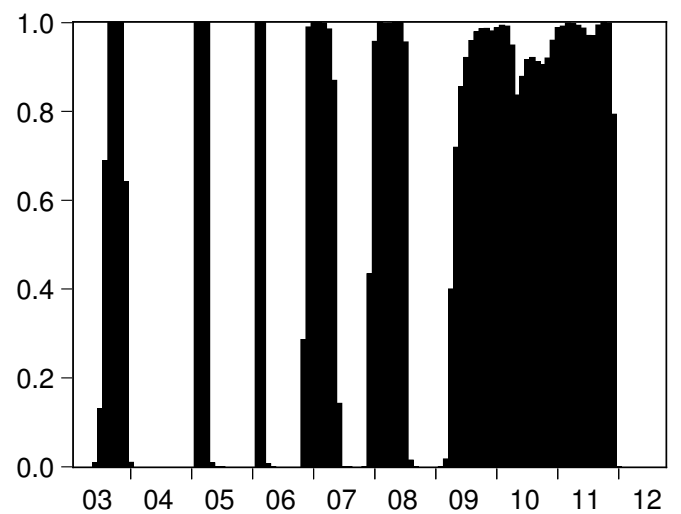

REGIME 3

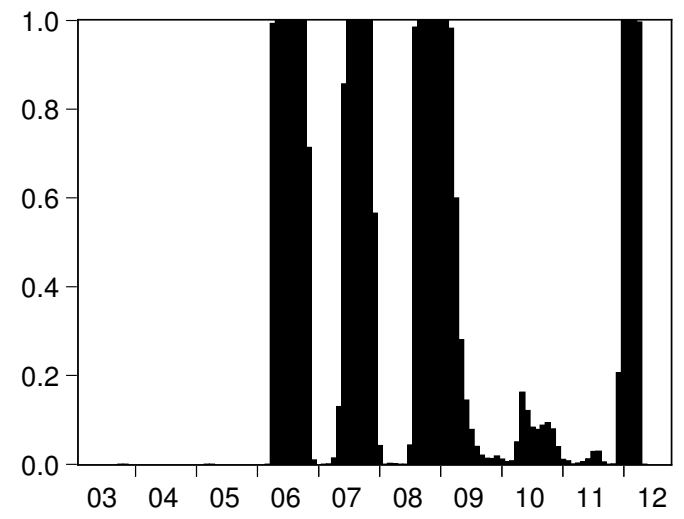

Com relação ao crédito de modo geral, até a eclosão da crise financeira de 2008 os bancos privados tiveram a frente na expansão do crédito. A partir de 2009, observou-se a retomada do processo de crescimento do crédito com a elevação de $15,2 \%$ no saldo das operações de crédito do Sistema Financeiro Nacional (SFN). Tal elevação foi liderada pelos bancos públicos. Este processo foi, em grande parte, decorrente de medidas anticíclicas adotadas pelo governo federal, no intuito de mitigar os efeitos da crise. Em 2009, notou-se uma expansão acentuada $(29,1 \%)$ do crédito direcionado, e um aumento 
da participação dos bancos públicos no total de crédito do SFN, que passou de 36,3\% em 2008 para $41,5 \%$ em 2009. Assim, é natural supor que o governo tenha feito uso do crédito habitacional como instrumento de política anticíclica assim como meta de política a partir de 2009.

De modo a validar a análise deste trabalho, será analisado se os resultados dos coeficientes ${ }^{44}$ das regressões para cada estado no modelo de três regimes, mostrados na Tabela 4, corroboram as colocações postas anteriormente. Com relação à taxa de financiamento representada pela Selic, observa-se que é no estado 1 , anterior ao ciclo de expansão do crédito imobiliário, que esta variável apresenta menor efeito sobre a demanda de crédito indicando que a demanda neste regime é pouco sensível à mudanças na taxa de juros. Embora isso possa ter várias explicações é razoável a colocação que no período até onde se concentra o regime até o final de 2005, a taxa Selic esteve num nível bem elevado. Foi desta data em diante que começou a se acentuar a tendência de queda da Selic. ${ }^{45}$ Pode ser então que antes disso acontecer, dado o alto nível, uma mudança na Selic não alterava substancialmente a motivação para se demandar crédito habitacional. Quando a taxa de juros chegou num patamar atrativo, a demanda começou a responder com maior intensidade. Observa-se que o efeito de uma mudança marginal da taxa Selic nos regimes 2 e 3 é bem mais acentuado.

Table 4: Modelo MS(3)-AIH* Variável dependente: FIMOB

\begin{tabular}{l|c|c|c}
\hline & Regime 1 & Regime 2 & Regime 3 \\
\hline CONST & $-3.149(0.021)$ & $-25.680(0.000)$ & $-45.133(0.000)$ \\
\hline SELIC & $-0.085(0.011)$ & $-0.743(0.000)$ & $-0.622(0.005)$ \\
\hline PRIMOV* & $3.290(0.000)$ & $1.900(0.000)$ & $1.432(0.000)$ \\
\hline RENDA & $-0.935(0.000)$ & $3.329(0.000)$ & $6.714(0.000)$ \\
\hline INDCC & $0.296(0.000)$ & $0.378(0.021)$ & $1.079(0.000)$ \\
\hline Desvio-Padrão & $0.019(0.000)$ & $0.052(0.000)$ & $0.087(0.000)$ \\
\hline OBS & 32 & 55 & 38
\end{tabular}

${ }^{*} p$-valor entre parênteses. As variáveis tomadas no log

Conforme foi dito acima, usa-se a variável que INDCC como variável de controle, mas esta variável pode também dar uma ideia de confiança no setor. Tendo isso em mente, podemos ver que no regime 3, definido anteriormente como sendo aquele onde a demanda por crédito é melhor explicada pelos fundamentos de mercado, o coeficiente desta variável mostra o maior coeficiente. Outro ponto que corrobora a nossa análise é que também no caso da variável RENDA, o maior coeficiente está relacionado ao regime 3. Interessante notar que o coeficiente dessa variável no regime 1 é negativo. Isto parece indicar que devido às imperfeições não apenas no mercado de crédito mas também do mercado imobiliário neste regime, no caso de uma elevação na renda os agentes destinavam este aumento para outros bens.

Vejamos agora como analisar a influência do preço dos imóveis (PRIMOV*) em cada regime. Verifica-se que o efeito do preço no regime 1 é muito mais acentuado que nos outros dois regimes. Combinando este resultado com os demais já analisados para as demais variáveis, percebe-se que nesse

\footnotetext{
${ }^{44}$ As estatísticas de erro padrão foram numericamente calculadas por meio do Hessiano da função de log verossimilhança no ponto de máximo. Infelizmente, essas aproximações não são necessariamente precisas. Assim, os resultados $p$-valores devem ser interpretados com cautela.

${ }^{45}$ Conforme já foi colocado, no âmbito do SFH a taxa de financiamento é limitada em $12 \%$ a.a. mais TR (taxa referencial). Deve-se, no entanto, tem em mente que TR somente no período mais recente a partir do início de 2009 que esta taxa começou a apresentar tendência acentuada de queda. Em julho de 2003, a TR chegou a 6,15\% a.a. Deve-se ainda considerar que a taxa referencial tem sofrido diversas mudanças na metodologia de cálculo desde que foi criada desde 1991.
} 
estado o preço do imóvel é a variável mais importante para explicar a demanda de crédito imobiliário. Pois, tendo em vista as imperfeições deste mercado, uma variação no preço do imóvel seria capaz de impor um efeito substancial sobre a demanda por crédito comparado ao efeito que outras variáveis teriam. Com relação aos regimes 2 e 3, nota-se que o coeficiente da variável PRIMOV* decresce de valor nesses dois regimes com relação ao estado 1 . Contudo, o preço se destaca bem mais no regime 2 dando a impressão que o que poderia estar acontecendo é que neste regime as pessoas estariam sendo motivadas a demandar hipoteca por força do aumento futuro do preço do imóvel.

Table 5: Probabilidades de Transição

\begin{tabular}{l|c|c|c}
\hline & \multicolumn{3}{|c}{ Em $t+1$} \\
\hline \multirow{2}{*}{ Em $t$} & Regime & Regime & Regime \\
& 1 & 2 & 3 \\
\hline \multirow{2}{*}{ Regime 1 } & 0.907 & 0.001 & 0.072 \\
& $(0.000)$ & $(0.000)$ & $(0.000)$ \\
\hline \multirow{2}{*}{ Regime 2 } & 0.037 & 0.879 & 0.084 \\
& $(0.154)$ & $(0.000)$ & $(0.000)$ \\
\hline \multirow{2}{*}{ Regime 3 } & 0.036 & 0.120 & 0.841 \\
& $(0.314)$ & $(0.064)$ & $(0.000)$ \\
\hline
\end{tabular}

Por fim, passando agora à análise da matriz de transição de probabilidades (Tabela 4), notamos que, uma vez dentro de cada um dos três regimes, existe uma alta probabilidade de permanência. No entanto, é o regime 1 que mostra maior inércia. Assim, é preocupante tendo em vista o gráfico da datação dos regimes na Figura 1 que no período mais recente, a partir do final de 2011, a demanda por concessão de crédito imobiliário esteja novamente inserida neste estado. Pode ser o caso que o ciclo de crescimento da demanda por crédito imobiliário esteja sofrendo forte retração pelo fato da capacidade de endividamento estar chegando num ponto limite. Uma forma de verificar a razoabilidade desta assertiva é olhar para a condição atual de endividamento das famílias. No Apêndice F, mostramos as séries de endividamento das famílias com e sem crédito imobiliário. Embora o endividamento com o crédito imobiliário pareça ainda ser baixo, o mesmo não se verifica quando olhamos para o total que em março de 2013 já se encontra acima de $40 \%$ em relação à renda acumulada no período de doze meses.

Portanto, pelo menos numa primeira análise parece razoável chamar atenção para o fato de um possível esgotamento da capacidade de endividamento das famílias e seu efeito sobre o mercado imobiliário. Contudo, deve-se considerar que devemos em princípio examinar o horizonte deste endividamento. De qualquer forma, tendo em vista a condição macroeconômica atual com o retorno da inflação, temos que considerar uma provável elevação da taxa de juros e o efeito disso sobre o endividamento e a inadimplência. Esta mudança de cenário poderá causar efeito imediato no mercado imobiliário pela sua forte dependência do crédito. Tentaremos lançar luz sobre este ponto na próxima seção.

\section{EFEITO DE UM CHOQUE MONETÁRIO SOBRE O SETOR IMOBILIÁRIO}

\subsection{Introdução}

Existe certo consenso que dois fatores estão entre os principais determinantes para o desencadeamento da crise no mercado imobiliário americano que aconteceu em 2007-2008. Primeiro, as diversas medidas de direcionamento de crédito para o setor habitacional para pessoas de baixa 
renda. Desde 1999, a Fannie Mae, cuja pressão começou na administração Clinton, forçou a expansão dos empréstimos hipotecários para os mutuários de renda baixa e média, aumentando os índices da carteira de crédito das instituições financeiras em zonas urbanas problemáticas designadas no Ato de Reinvestimento Comunitário (CRA $)^{46}$ de 1977. As instituições financeiras do mercado de hipotecas eram pressionadas mesmo de modo indireto pelas GSEs para diminuir as exigências para a concessão de crédito. ${ }^{47}$ Em segundo lugar, a longa tendência de queda da taxa básica de juros do Federal Reserve ${ }^{48}$ que teve início ao final de 2000 saindo de 6,5\% a.a. em dez/00 até chegar a 1,01\% a.a. em jun/04 também teve consequências desastrosas.

Muitas foram as consequências da permanência por um longo período da taxa da Reserva Federal ${ }^{49}$ num nível muito baixo em relação ao seu nível histórico. Primeiro, isso gerou um aumento no valor do imóvel forçando a mudança na composição da carteira de ativos. Segundo, a taxa ajustável para hipotecas (ARM) ${ }^{50}$ cujo ajuste tem por base a variação no período de um ano na taxa básica se tornou muito mais barata que a taxa fixa de 30 anos. ${ }^{51}$ Com efeito, aconteceu um grande aumento do volume de novas hipotecas com base em taxas ajustáveis, sendo que o número desses contratos mais que dobrou entre 2001 e 2004. O castelo de cartas desmoronou com o retorno da inflação que começou a se elevar já no início de 2004. O aumento da inflação forçou uma inevitável resposta na taxa básica de juros que saiu de 1,01\% a.a. em jun/04 até chegar a 5,25 em jul/06 permanecendo assim até ago/08. A crise eclodiu logo em seguida.

Muito embora exista a ideia disseminada de que o seguimento subprime foram os responsáveis pela crise no mercado imobiliário americano de 2008, o fato é que isso não é bem assim. O foco no mercado subprime ignora o fato de que $51 \%$ dos títulos inadimplentes pertenciam ao segmento prime sendo que a variação da inadimplência neste mercado foi de $488 \%$ enquanto que no segmento subprime foi de $200 \%$. Isso não significa dizer que historicamente o nível de inadimplência no mercado subprime não fosse maior, o que em condições normais é o que prevalece. Deve-se ter em mente, que o grau de inadimplência era até então muito baixo no segmento prime. Ressalta-se ainda que o aumento na inadimplência ocorreu muito rapidamente. A escalada se iniciou no terceiro semestre de 2006 alcançando o pico ao final de 2007 (pag. 19 Leibwitz, 2008).

Pode-se questionar quais lições do que aconteceu no mercado imobiliário americano servem para o mercado brasileiro, tendo em vista que no Brasil a taxa básica de juros alcançou um nível muito baixo, enquanto é sabido que o governo tem feito uso da expansão do crédito direcionado como instrumento ativo de política. Concomitantemente, percebe-se um recrudescimento da inflação, que em março de 2013 atingiu 6,58\% em relação ao mesmo período do ano anterior, ultrapassando o teto da meta de 6,5\% para o ano. Naturalmente, é difícil acreditar que se a inflação persistir na atual tendência de alta, a taxa de juro não irá aumentar. Assim, é oportuno procurar responder que consequências um aumento na taxa de juros teria não apenas sobre a demanda por crédito imobiliário mas também sobre outras variáveis relevantes.

Pois, mesmo que o governo intensifique a política de subsidiar a taxa de juros para financiamento imobiliário, o crescimento desta pode afetar negativamente o setor por meio da queda da renda real e

\footnotetext{
${ }^{46}$ Community Reinvestiment Act.

${ }^{47}$ Destaca-se aqui a redução ou mesmo a isenção do chamado “down payment” (parte paga a vista do valor do imóvel), aceitação de ganhos não convencionais (que não possuem comprovação formal como biscates e trabalhos temporários) na composição da renda, diminuição da relevância da análise histórica de crédito e aceitação de um coeficiente dívida/renda acima do convencional. Em relação a este último item é norma usual do mercado não conceder empréstimo cujo desembolso supere um terço da renda bruta do mutuário.

${ }^{48}$ Federal Fund Rate.

${ }^{49}$ Federal Fund Rate.

${ }^{50}$ Adjustable-rate mortages.

${ }^{51} \mathrm{~A}$ taxa ajustável (ARM) saiu de 7,0\% em jan/01 para 4,0\% em jan/04 enquanto a taxa fixa (fixed rate) que em jan/01 estava um pouco acima de $7,0 \%$ nunca esteve abaixo de $5,5 \%$ no mesmo período.
} 
o nível do produto o que impactaria no desemprego. Todos estes fatores podem levar ao aumento da inadimplência gerando queda no preço dos imóveis e do produto da construção civil.

Em uma interessante análise acerca do canal de crédito bancário da política monetária, Bernanke e Gertler (1995) usando dados da economia americana destacam que um dos fatos estilizados ligados à ocorrência de um choque monetário é uma queda rápida e acentuada no investimento residencial mesmo tendo em vista que o aumento da taxa nominal de juros é transitório. Isso é de se estranhar, pois seria de se esperar tendo em vista a teoria neoclássica tradicional que o investimento habitacional em capital fixo tivesse maior relação com a taxa de juros de longo prazo e fosse menos relacionada à taxa de curto prazo.

Apresentam-se algumas justificativas para explicar por que razão o investimento habitacional reage de modo rápido e intenso a uma mudança na taxa de juros. Imagina-se uma situação tal como aconteceu nos Estados Unidos em 2008 na qual os preços se elevaram intensamente for força do direcionamento do crédito culminando em um processo de formação de bolha especulativa. Em tal situação, o aumento da taxa de juros levou ao aumento da inadimplência gerando queda no preço dos imóveis e retração do investimento habitacional em um processo que se realimentou até chegar ao total colapso do mercado imobiliário. Obviamente, também ocorrerá queda na demanda e na oferta por novos financiamentos imobiliários.

No caso da queda imediata e sustentada do investimento residencial em decorrência de uma elevação da taxa de juros nominal, pode-se imaginar que isso estaria sendo causado pela contração da oferta de recursos para empréstimos. O ponto aqui é que o que se observa a partir das estatísticas de financiamentos imobiliários não é a oferta, mas a interação entre a oferta e a demanda de financiamento. Deste modo, é necessário fazer uso de um processo de identificação para que algo fidedigno possa ser dito a respeito do que acontece com o financiamento imobiliário em decorrência da elevação da taxa de juros. Felizmente, no caso brasileiro por consequência do direcionamento do crédito no setor imobiliário a questão da causalidade reversa perde significado, o governo fixa ou limita o preço (taxa de financiamento) ofertando recursos para concessão de empréstimos de modo a atender a demanda. Portanto a identificação ocorre no sentido que o preço (taxa de financiamento) afeta a demanda, mas não o contrário.

De modo a inferirem-se as consequências incidentes sobre o mercado imobiliário advindas do efeito de uma política monetária mais restritiva, implementada com base num aumento inesperado da taxa básica de juros, será feito uso do modelo VAR estrutural. ${ }^{52} \mathrm{O}$ modelo VAR estrutural é um modelo ateórico que utiliza um conjunto pequeno de variáveis que têm como objetivo captar informação relevante do fenômeno econômico que se pretende estudar. Uma ampla literatura sobre modelos de VAR estrutural tem sido aplicada para se analisar os efeitos de choques monetários na economia ${ }^{53}$ assim como em estudos acerca do efeito da política fiscal. ${ }^{54}$ Contudo, esta metodologia também tem sido empregada para verificar o efeito de um choque de política monetária sobre o mercado imobiliário (Kahn, 1989, Pozdena, 1990, Ryding, 1990, McCarthy e Peach, 2002, Miskin, 2007, inter allia). ${ }^{55}$

\subsection{VAR Estrutural (SVAR)}

O VAR estrutural (SVAR $)^{56}$ pode ser representado da seguinte maneira:

\footnotetext{
${ }^{52}$ Para maiores detalhes sobre a modelo VAR pode ser encontrado em Sims (1986), Fackler (1988), Hamilton (1993) e Enders (1995).

${ }^{53}$ Ver Christiano et alii (1999) para uma revisão desta literatura.

${ }^{54}$ Blanchard e Perotti (2002), Fatas e Mihov (2001b,a), Favero (2001), Gali et alii (2004), Romer e Romer (1994), Ramey e Shapiro (1998), Edelberg et alii (1999), Burnside e Fisher (2003), inter allia.

${ }^{55} \mathrm{~A}$ valorização do patrimônio residencial estimula a aquisição de outro imóvel de padrão superior.

${ }^{56}$ Para maiores detalhes sobre a modelo VAR pode ser encontrado em Sims (1986), Fackler (1988), Hamilton (1993) e Enders (1995).
} 


$$
A Y_{t}=\alpha+\sum_{i=1}^{p} A_{i} Y_{t-i}+\varepsilon_{t} \text { para } t=0: T
$$

Se assumirmos que $A$ é inversível, então (1) tem a forma reduzida dada por:

$$
Y_{t}=\beta+\sum_{i=1}^{p} B_{i} Y_{t-i}+u_{t}
$$

com $u_{t} \sim N\left(0, \sum\right)$ e $E\left(u_{t} u_{s}^{\prime}\right)=0, \forall t \neq s$, onde $u_{t}$ é a forma reduzida dos resíduos e $\beta$ é um vetor de constantes. Assumimos que $\varepsilon_{t} \sim N(0, I)$. A relação entre os modelos (1) e (2) é baseada nas seguintes equações:

$$
\beta=A^{-1} \alpha, B_{i}=A^{-1} A_{i}, u_{t}=A^{-1} \varepsilon_{t}, \text { e } \sum=A^{-1} E\left(\varepsilon_{t} \varepsilon_{t}^{\prime}\right)\left(A^{-1}\right)=A^{-1}\left(A^{-1}\right)
$$

Note que tal representação não permite a identificação de choques exógenos independentes nas variáveis, isso ocorre pois os resíduos das formas reduzidas são contemporaneamente correlacionados (a matriz $\sum$ é não diagonal). ${ }^{57}$ Isto é, os resíduos da forma reduzida $u_{t}$ podem ser interpretados como resultado de uma combinação linear de choques exógenos que não são correlacionados contemporaneamente. Não é possível distinguir qual o choque que afeta determinada variável na forma reduzida. Para a avaliação de política somente faz sentido verificar o efeito de um choque independente. É possível estimar os parâmetros $B$ e $\sum$ em (2) de maneira consistente mas, exceto para previsão, eles não são parâmetros de interesse. Sem restrições adicionais em $A$ nós não podemos recuperar a forma estrutural a partir da forma reduzida, pois $\sum$ não possui coeficientes estimados em número suficiente para se recuperar a matriz não-restrita $A$. Dessa maneira, precisamos impor um número de restrições que tornem possível a identificação e estimação de $A$. Este procedimento é conhecido por identificação.

A matriz $A$ pode ser estimada por meio das informações presentes na matriz de covariância da forma reduzida. $O$ ponto importante aqui é que, geralmente, existe um grande número de matrizes de posto completo $A$ que nos permite reproduzir $\hat{\sum}$. Isto é, existem várias condições de dependência e independência nas correlações contemporâneas (Núcleos de Markov) ${ }^{58}$ entre as variáveis - dadas pelas diferentes especificações onde os parâmetros em $A$ são livres ou restritos igual a zero - que nos permitem reproduzir as correlações parciais observadas dos resíduos na forma reduzida. ${ }^{59}$ Isso significa que $A^{-1}\left(A^{-1}\right)=\tilde{A}^{-1}\left(\tilde{A}^{-1}\right)$ onde $\tilde{A}$ é a decomposição de Choleski para $\hat{\sum}$. Resumindo, existem várias maneiras de se decompor $\hat{\sum}$.

Para se estimar um modelo estrutural é necessário identificar um número de relações condicionais independentes (isto é, parâmetros iguais a zero em $A_{0}$ ) para satisfazer a condição de ordem para identificação. Dessa maneira, identificar $A$ é equivalente a identificar a distribuição condicional ("Markov Kernels") dos resíduos da forma reduzida das informações sobre suas distribuições conjuntas. O procedimento de identificação determina a ordem de causalidade entre as variáveis endógenas do VAR estrutural. De acordo com Uhlig (2005) a identificação é feita usualmente seguindo-se um dos três

\footnotetext{
${ }^{57}$ Tais choques são forças primitivas e exógenas, sem causa comum, que afetam as variáveis do modelo.

${ }^{58}$ Markov Kernels.

${ }^{59} \mathrm{~A}$ matriz $A$ não pode ter, em seu conjunto, um número de parâmetros livres maior do que o número de parâmetros livres na matriz simétrica $\sum$. Se $n$ for o número de variáveis endógenas do modelo então, para satisfazer à condição da ordem para a identificação de $A$, é necessário que o número de parâmetros livres a ser estimado em $A$ seja não maior do que $n(n-1) / 2$. Quando $n$ é menor do que $n(n-1) / 2$ o modelo é sobre-identificado. Não existe uma condição geral simples para a identificação local dos parâmetros de $A$. Uma condição, como foi mostrado por Rothenberg (1971), necessária e suficiente para a identificação local de algum ponto regular no $R^{n}$ é que a determinante da matriz da informação seja diferente de zero. Na prática, as avaliações da determinante da matriz da informação em alguns pontos, escolhida aleatoriamente no espaço dos parâmetros, são o bastante para estabelecer a identificação de um determinado modelo.
} 
seguintes métodos: i) aplicando-se a decomposição de Cholesky na matriz de covariância dos resíduos $\sum$ o que implica num ordenamento recursivo (Sims, 1986). Impor alguma relação estrutural na matriz $A$ (Bernanke, 1986), ou separando impulsos transitórios de permanentes nos impulsos primários $\varepsilon_{t}$ (Blanchard e Watson, 1986).

\subsection{Modelo}

Conforme dito, o objetivo desta seção é analisar o efeito de um choque de política monetária, representado pelo aumento da taxa básica de juros (SELIC), sobre o mercado imobiliário. Naturalmente ao selecionar as variáveis do modelo, deve-se levar em consideração que as variáveis representativas do mercado imobiliário interagem naturalmente com outras variáveis da economia sofrendo os efeitos delas. Serão usadas quatro variáveis para representar o núcleo representativo do setor imobiliário que são as concessões de empréstimos imobiliários (FIMOB) dentro do SFH, a inadimplência (INAD) e índice do produto industrial da construção civil $^{60}$ (INDCC) e o índice de preço dos imóveis (PRIMOV). Com relação às variáveis macroeconômicas escolheu-se trabalhar com o índice de preços ao consumidor amplo (IPCA), a renda do trabalho principal (RENDA) ou a taxa de desemprego (DESP) além da taxa básica de juros (SELIC). O período analisado foi de janeiro de 2003 a setembro de 2012 . O gráfico das variáveis é mostrado no Apêndice $C$.

A identificação do VAR estrutural se faz aqui a partir do emprego do método de gráficos acíclicos dirigidos (GADs) (Spirtes et alii, 1993, 2000) para determinar a ordenação de causalidade contemporânea do SVAR. Esta técnica explora a possibilidade de inferir causalidade a partir dos dados. Ela testa as relações de independência condicional entre as variáveis observadas que com base em determinadas hipóteses impõe restrições gráficas sobre as possíveis estruturas causais. Neste artigo foi utilizada a metodologia baseada em restrições ${ }^{61}$ desenvolvido por Spirtes et alii (1993) com objetivo de identificar ordenações causais contemporâneas das variáveis dos SVARS a fim de identificar os modelos. ${ }^{62}$

Swanson e Granger (1997) foram os primeiros a aplicar modelo de gráficos para identificar ordem causal contemporânea de um SVAR. Bessler e Lee (2002) usaram modelo de correção de erro e DAGs para estudar as relações defasadas e contemporâneas para dados da economia americana. Demiralp e Hoover (2003) avaliaram o algoritmo utilizando método de Monte Carlo e concluiram que se trata de uma ferramenta eficaz de selecionar a ordem causal contemporânea de um SVAR. No Brasil Céspedes et alii (2008) aplicaram os GADs para obter fatos estilizados sobre as flutuações de curto prazo da economia brasileira após o Plano Real com atenção especial à identificação dos efeitos de um choque de política monetária.

Usando as ordenações selecionadas para identificar o SVAR, pode-se então gerar as funções de resposta do impulso (IRFs). Os GADs são identificados por meio do programa TETRAD usando o nível de significância ${ }^{63}$ de $0.5 \%$ na matriz de covariância dos resíduos e assumindo a hipótese de que as

\footnotetext{
${ }^{60}$ Insumos.

${ }^{61}$ Existe outra abordagem com base na estatística bayesiana que aplica técnicas de seleção de modelos bayesianos para a busca de um grafo causal usando dados para fazer inferências probabilísticas sobre restrições de independência condicional. Por exemplo, ao invés de aceitar que as variáveis são independentes, a abordagem bayesiana leva em conta a incerteza sobre a presença de independência.

${ }^{62}$ Usando a matriz de covariância das variáveis do VAR, podemos convertê-la em uma matriz de correlação e realizar testes de hipóteses em que a hipótese nula é a de correlação parcial zero. A busca começa com um gráfico padrão onde qualquer par de nós (variáveis) é acompanhado por uma seta não direcionada. Se a hipótese nula de correlação condicional zero não pode ser rejeitada, digamos ao nível de $5 \%$ utilizando o teste $z$ de Fisher o nó é suprimido. Depois de examinar todos pares de vértices, movimenta-se para um nó de três variáveis, e assim por diante, orientando as setas remanescente por meio da conexão entre independência probabilística e a teoria dos grafos.

${ }^{63}$ O nível de significância não pode ser interpretado como a probabilidade do erro do tipo 1, mas apenas um parâmetro de busca. Baseado em simulações para GAD geradas randomicamente, Spirtes et alii (2000) sugere um nível de significância de $20 \%$
} 
variáveis selecionadas para o modelo são causal suficientes, ${ }^{64}$ obtemos o que se denomina padrão. 0 padrão aqui é definido como uma representação gráfica de um conjunto de GADs que contêm as relações de causalidade contemporânea das variáveis.

\subsection{Resultados}

Inicialmente, aplicam-se os critérios de informação de Schwarz e Hannan-Quinn que tem como objetivo indicar o número de defasagens com que o VAR dever ser estimado. Tais critérios indicaram que o VAR deveria ser estimado com base em duas defasagens. Cumpre destacar que a estimação da função de reação acima é defensável mesmo na presença de raiz unitária nas variáveis. Felizmente, o problema da "regressão espúria" pode ser contornado por meio da introdução dos valores defasados das variáveis I(1) entre as variáveis explicativas da regressão (Hamilton, 1993, Sims et alii, 1990). Com efeito, Hamilton (pp. 561-562 1993) assinala que tal procedimento assegura uma estimação consistente para o modelo sem mudanças de regime. Ademais, pode ser demonstrado que, nesse último caso, as estatísticas " $t$ " para os coeficientes individuais são assintoticamente normais.

A seguir, com base na matriz de covariância dos resíduos do VAR, os GADs detectaram nove representações válidas de causalidade contemporânea. As relações derivadas do GADs entram em $A_{0}$ como restrições que ajudam no processo de identificação dessa matriz tal como definido acima. No Apêndice A, mostramos como aplicar a ordenação causal obtida do GADs para identificar a matriz $A_{0}$. As relações de causalidade identificadas com base nos GADs são as seguintes:

$$
\begin{aligned}
& \text { (1) FIMOB } \rightarrow \text { PRIMOV,(2)INDCC } \rightarrow \text { IPCA, (3)INDCC } \rightarrow \text { RENDA, } \\
& \text { (4) IPCA } \rightarrow \text { RENDA, (5)PRIMOV } \rightarrow \text { IPCA, (6)RENDA } \rightarrow \text { IPCA, } \\
& \text { (7) SELIC } \rightarrow \text { FIMOB, (8)SELIC } \rightarrow \text { PRIMOV }(9) I N A D \rightarrow \text { FIMOB }
\end{aligned}
$$

As funções de impulso-resposta (FRIs) de um choque monetário contracionista representado por um aumento inesperado da SELIC do tamanho de um desvio-padrão para um horizonte de 36 meses com base na identificação advinda dos GADs são mostrados na Figura 3. Inicialmente, é interessante notar que com relação ao IPCA não ocorre o chamado "price puzzle". ${ }^{65}$ Ao contrário, esta variável mostra uma queda forte e continuada. O mesmo acontece com a variável RENDA. No que se refere à Selic, nota-se que o choque tem efeito transitório sobre a taxa nominal de juros tal como aparece em Bernanke e Gertler (1995).

Passemos agora à análise das FRIs das variáveis representativas do setor imobiliário. De acordo com os resultados um choque contracionista de política monetária produz o efeito negativo sobre todas as variáveis do setor. As concessões de crédito habitacional (FIMOB) e o produto industrial da construção civil (INDCC) registram queda enquanto a inadimplência (INAD) aumenta. Todas as IRFs dessas variáveis

para amostras de tamanho menor que 100; 10\% para amostras de tamanho entre 100 e 300; e 10\% (ou menor) para amostras maiores.

${ }^{64}$ Um conjunto $V$ de variáveis é dito causal suficiente se qualquer causa comum de duas ou mais variáveis em $V$ está em $V$. O TETRAD tem um viés para exclusão de relação causal presente no dado. De modo a contornar essa limitação, o programa sugere que um nível de significância de $20 \%$ deve ser usado.

${ }^{65}$ o "price puzzle" ocorre quando o nível de preço aumenta em decorrência de um choque monetário. A literatura tradicional assinala que respostas a determinados choques inconsistentes com a teoria tal como o "price puzzle" indicariam a princípio que o modelo está mal especificado. Contudo, essa visão não é unânime na literatura. Pode-se argumentar ainda que diferentemente do que coloca corrente tradicional, é o canal de custo da política monetária que faz com que os preços e a taxa de juros nominal reajam na mesma direção depois de um choque de política monetária. Quando o Banco Central eleva a taxa de juros alguns custos aumentam, tendendo a causar um aumento na taxa de inflação. Este efeito do lado da oferta pode coexistir e dominar o tradicional efeito do lado da demanda (Rabanal, 2007). No modelo VAR estrutural usado por Bernanke e Gertler (1995) para extrair os fatos estilizados decorrentes de um choque monetário, o "price puzzle" se perpetua num horizonte de 12 meses. 
demonstram forte persistência com relação à média durante todo o horizonte temporal. No que se refere ao preço dos imóveis (PRIMOV), apesar do efeito ser na média levemente positivo ou próximo de zero durante os primeiros 15 meses, a partir desta datação existe uma reversão forte prevalecendo uma tendência de queda acentuada do preço dos imóveis. Assim, tais resultados corroboram o fato que um aumento na taxa de juros pode ter um forte impacto sobre o mercado imobiliário no Brasil.

Figure 3:

Resposta de Um Choque Estrutural de Um Desvio Padrão

FIMOB

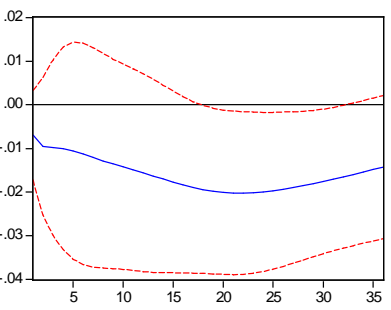

PRIMOV

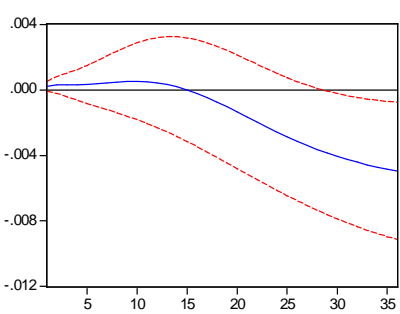

INDCC

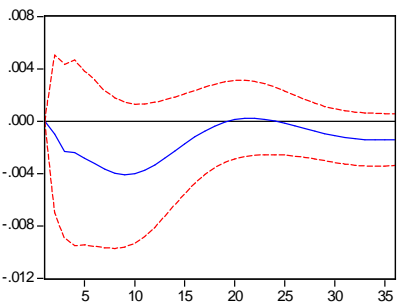

RENDA

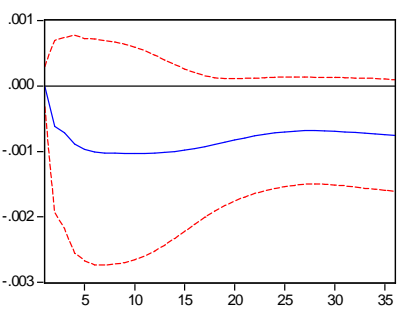

INAD

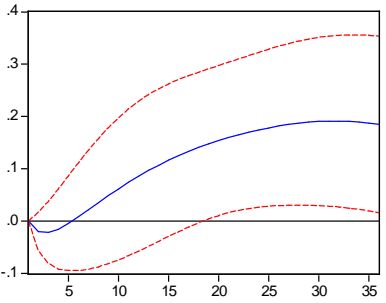

IPCA

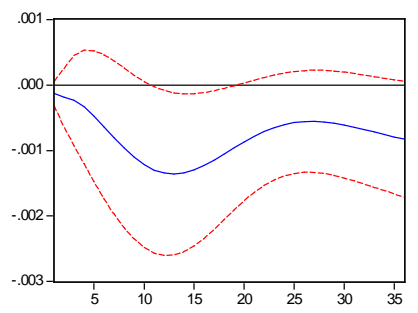

SELIC

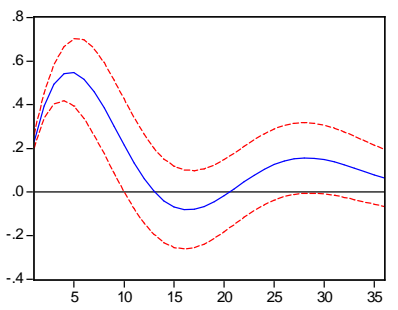

Combinando os efeitos registrados nas variáveis macroeconômicas com as variáveis relacionadas ao mercado imobiliário, podemos dar a seguinte interpretação. Um choque na taxa de juros induz a queda do PIB levando à queda na inflação. Também, o aumento da taxa de juros provoca o aumento da inadimplência Todos esses efeitos atuam em conjunto para provocar queda no preço dos imóveis que ocorre de modo defasado. $\mathrm{O}$ aumento na inadimplência pode se dar por dois motivos principais. O possível aumento do desemprego, por força da retração do PIB, em conjunto com a elevação da taxa de juros leva à redução da capacidade de honrar as hipotecas. Existe ainda o caso dos especuladores que entraram no mercado com intuito de repasse na expectativa do aumento contínuo do preço dos imóveis, o que terá termo frente ao aumento da taxa de juros e seus desdobramentos.

De modo a testar a robustez do nosso modelo, refazemos o exercício do VAR estrutural substituindo a variável INDCC pelo PIB. Os resultados das FRIs são mostrados na Figura 4. Também, o mesmo exercício 
para o VAR estrutural é feito substituindo a variável RENDA pela taxa de desemprego (DESP). As FRIs deste exercício aparecem no Apêndice D. Em nenhum dos dois destes exercícios para validar a robutez do modelo, observou-se que alteração qualitativa dos resultados. ${ }^{66}$

Figure 4:

Resposta de Um Choque Estrutural de Um Desvio Padrão da Selic

FIMOB

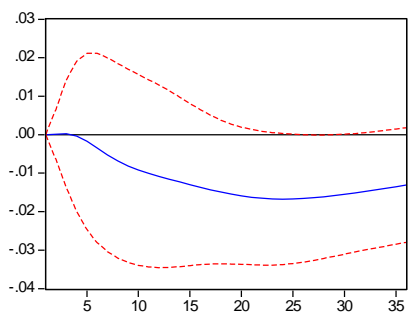

PIB

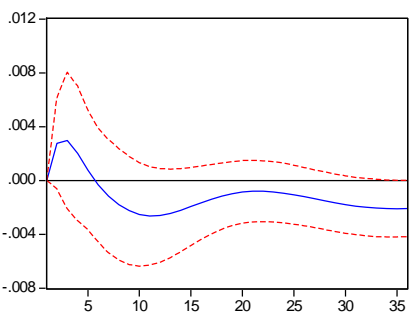

PRIMOV

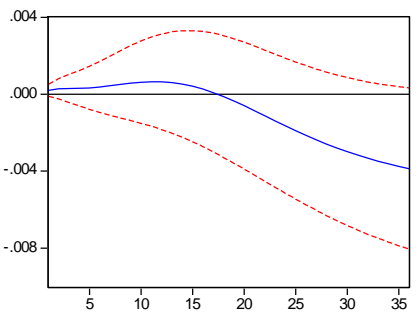

SELIC

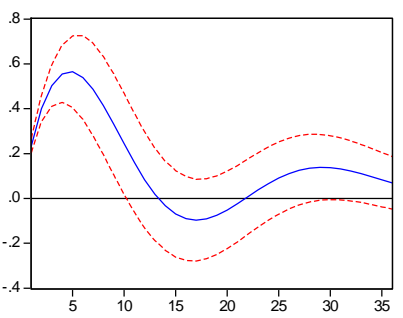

RENDA

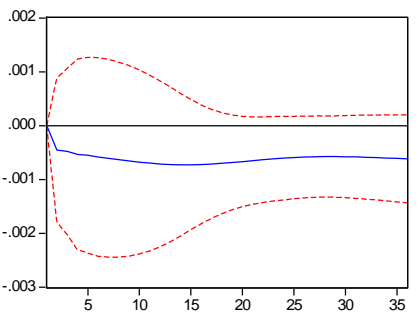

IPCA

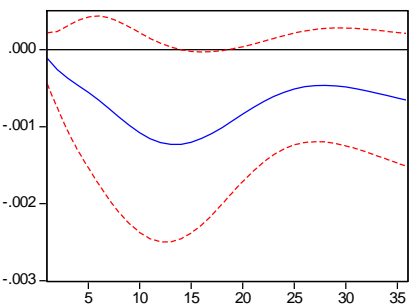

INAD

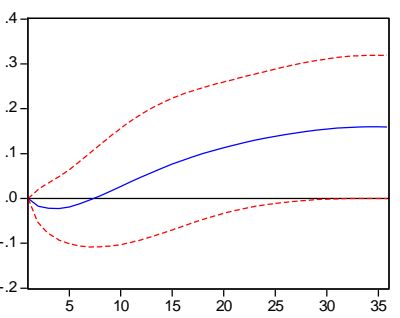

\section{ANÁLISE E PERSPECTIVAS FUTURAS}

Nesta seção analisaremos com base nos resultados obtidos as perspectivas futuras em relação ao mercado imobiliário brasileiro tendo em vista o que projeta para o cenário macroeconômico no médio prazo. Com este objetivo consideramos relevante observar a evolução recente de algumas variáveis econômicas que incidem de forma direta no mercado imobiliário e na condição do crédito. Tais variáveis assim como a trajetória assumida para elas entre janeiro e agosto de 2013 são mostradas na Tabela 6. Alguns comentários podem ser feitos a partir desta tabela.

\footnotetext{
${ }^{66}$ Por economia, omitimos as relações de causalidade contemporânea indicadas pelos GADs que podem ser informadas pelos
} autores mediante contato. 
Table 6:

\begin{tabular}{|c|c|c|c|c|c|c|c|}
\hline 2013 & $\begin{array}{l}\text { PRIMOB* } \\
\text { (1) }\end{array}$ & $\begin{array}{l}\text { INFLA } \\
(2)\end{array}$ & $\begin{array}{l}\text { ALUG* } \\
\text { (3) }\end{array}$ & $\begin{array}{c}\text { TXALG } \\
(\%) \\
(4)\end{array}$ & $\begin{array}{c}\text { ENDTOT } \\
(\%) \\
(5)\end{array}$ & $\begin{array}{c}\text { FOCUS } \\
\text { (a.a.) } \\
(6)\end{array}$ & $\begin{array}{c}\text { SELIC } \\
\text { (a.a.) } \\
\text { (7) }\end{array}$ \\
\hline JAN & 0.99 & 0.86 & 1.63 & 0.40 & 43.57 & 4.89 & 7.11 \\
\hline FEV & 1.30 & 0.60 & 1.70 & 0.40 & 43.79 & 4.70 & 7.13 \\
\hline MAR & 1.33 & 0.47 & 1.70 & 0.40 & 44.00 & 4.28 & 7.15 \\
\hline ABRIL & 1.24 & 0.55 & 1.41 & 0.40 & 44.21 & 4.34 & 7.26 \\
\hline MAIO & 1.19 & 0.37 & 0.57 & 0.40 & 44.52 & 4.61 & 7.42 \\
\hline JUN & 1.36 & 0.26 & 0.21 & 0.39 & 44.82 & 5.20 & 7.90 \\
\hline JUL & 1.50 & 0.03 & 0.04 & 0.39 & ND & 6.42 & 8.23 \\
\hline AGO & 1.17 & 0.24 & -0.07 & 0.38 & ND & 7.34 & 8.45 \\
\hline
\end{tabular}

Após longo período de otimismo no mercado imobiliário que começou desde 2008, o cenário parece se inverter. O preço do aluguel (ALUG) no Rio de Janeiro ${ }^{67}$ apresenta os primeiros sinais dessa mudança onde a variação no preço para locação teve seu primeiro revés se mostrando negativa no mês de agosto de 2013. Dados do ImovelBid ${ }^{68}$ somente na cidade de São Paulo existe um estoque de imóveis "encalhados" que a preço de mercado alcança $\mathrm{R} \$ 11,6$ bilhões. Em termos de unidades são cerca de 20 mil imóveis novos prontos e que não foram vendidos pela incorporadora. Também segundo o Secovi-SP, ${ }^{69}$ a média mensal de imóveis em estoque na cidade em 2013. Isso é preocupante, pois isso é pouco menos do total de lançamentos na cidade em 2013, segundo de São Paulo que até o mês de setembro 23.196 unidades lançadas. $^{70}$ Constata-se que $80 \%$ desses imóveis "encalhados" foram lançados em pleno boom imobiliário, há cerca de três anos, como resposta à alta dos preços.

Estranhamente, como pode ser visto na coluna (1) da Tabela 6, apesar da retração das vendas o preço do imóvel ainda não sofreu retração. O que pode explicar este fato? Em primeiro lugar é sabido que no caso do imóvel o preço de venda não possui um ajustamento rápido tal como foi mostrado na Seção 5 quando verificamos que o preço de venda do imóvel pode levar mais de quinze meses para se ajustar a aumento da taxa de juros devido a uma choque monetário. Segundo, durante a fase de construção ou mesmo até a venda, as construtoras reajustam o preço pelo INCC $^{71}$ o que cria uma base de sustentação para o preço do imóvel. Por último, acreditamos que embora o ajuste ainda não esteja acontecendo via preço, ele pode estar acontecendo por meio da maior facilidade para obtenção de crédito e na condição de pagamento incluindo também aqui menor entrada. ${ }^{72}$ Contudo, se este for o caso, isso poderá se tornar crítico adiante na medida em que o mercado pode estar admitindo mutuários com capacidade financeira duvidosa.

Outro fato intrigante é que existe um descolamento entre o preço do aluguel e o preço de venda do imóvel. Isso é visto no Gráfico 2. O descolamento entre essas duas variáveis por um longo período é um

\footnotetext{
${ }^{67} \mathrm{O}$ mesmo padrão se verificou para a cidade de São Paulo.

${ }^{68}$ Site especializado em leilões de estoques imobiliários.

${ }^{69}$ Sindicado do mercado imobiliário, sucursal da cidade de São Paulo.

${ }^{70}$ Folha de São Paulo, 17 de setembro de 2013.

${ }^{71}$ Índice Nacional da Construção Civil.

72 “Down payment".
} 
forte indício de bolha especulativa. De acordo com Robert Shiller, ${ }^{73}$ economista que previu o colapso do mercado imobiliário americano, existe forte indício de formação de bolha no mercado imobiliário brasileiro sendo que tal componente fortemente especulativo foi gerado, sobretudo, pela expansão do crédito, o que já teria sido apontado no Brasil por outros economistas (ver Mendonça e Sachsida, 2012). Isso também é apontado no presente como principal fator que alimentou as concessões de crédito para financiamento imobiliário durante a segunda fase do ciclo de expansão dessa modalidade de crédito. ${ }^{74}$

\section{Gráfico 2 -}

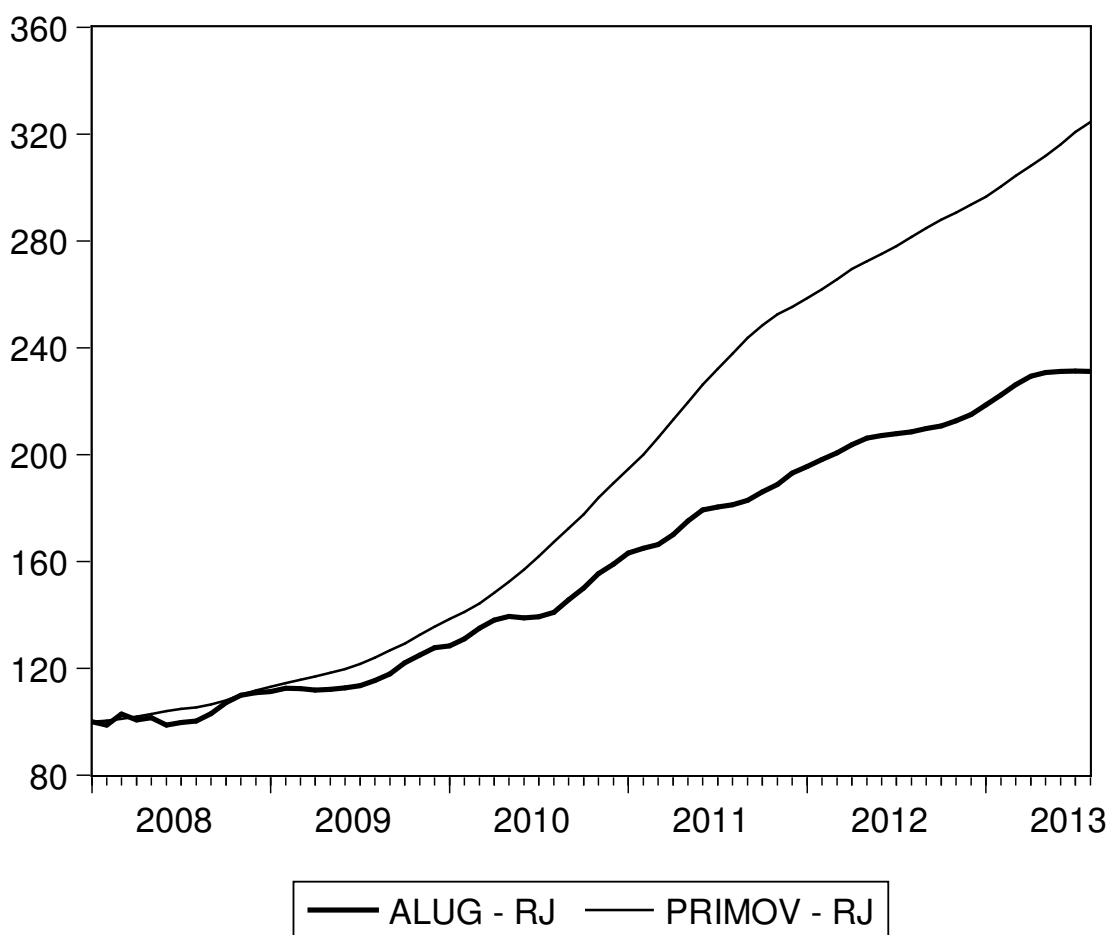

O ponto que devemos estar atento é que cedo ou tarde deverá haver um realinhamento entre os preços do aluguel e venda do imóvel, sendo que, caso isso aconteça, o cenário mais provável é que a trajetória do preço de venda convirja para o preço do aluguel, ou seja, de uma queda no valor do imóvel. Existem indícios de que este seja o cenário mais provável. Podemos ver na Tabela 6 que a expectativa de inflação (FOCUS) ${ }^{75}$ mostra tendência de crescimento devido à existência de um processo inflacionário já incorporado às expectativas dos agentes. Como consequência, o Banco Central, após um longo período de declínio, tem já há alguns meses implementado a elevação da taxa básica Selic nos últimos meses. Conforme foi visto na seção anterior, o efeito de um choque monetário irá causar retração no mercado imobiliário, pois tanto o volume de financiamentos assim como o preço de venda sofrerá retração.

\footnotetext{
${ }^{73}$ Sexto Congresso Internacional de Mercados Financeiro e de Capitais realizado pela BM\&F Bovespa, setembro de 2013.

${ }^{74}$ Ver Seção 4.

${ }^{75}$ Média tomada para todos os dias do mês da expectativa de inflação para o mês seguinte. Fonte: Banco Central do Brasil.
} 
Por fim, cabe mencionar que o nível global de endividamento já se situa em $45 \%$. Tendo em vista que se projeta um cenário de recessão para a economia brasileira pelo menos no médio prazo, a atitude do governo em querer aprofundar a expansão do crédito habitacional tem probabilidade não desprezível de acarretar grandes problemas no futuro como insolvência dos mutuários, acúmulos de estoques, etc., na medida em que a trajetória da inflação e da taxa de juros se mantenha ascendente. Costuma-se usar como justificativa para descartar a hipótese de formação de bolha no Brasil o fato que a participação do crédito imobiliário no PIB é baixa em comparação a de outros países. Contudo, acreditamos que no que diz respeito à formação de bolha o importante é a velocidade de expansão ou mesmo a aceleração do crédito, que foi muito expressiva nos últimos cinco anos. $O$ fato de que a relação crédito imobiliário/PIB é ainda muito baixa no Brasil serve apenas no nosso entendimento para descartar completamente a ideia de que um eventual problema no mercado imobiliário poderia contaminar o restante da economia como aconteceu nos Estados Unidos em 2008. Diferentemente, uma retração mais forte da economia certamente causará problemas ao setor.

Ao invés de fomentar o crédito de modo artificial, o governo poderia atuar no mercado imobiliário de maneira positiva tal como eliminando certos entraves de modo a fazer com que o este mercado funcione de modo maneira mais eficiente. Entre esses problemas podemos citar os seguintes. A escassez de terrenos nas grandes cidades. Dificuldade e alto custo para em se aprovar qualquer projeto. Na cidade de São Paulo isso leva dois anos em média. Grande custo referente à burocracia que o pais tem em relação à documentação, registro de imóveis etc. Tais entraves limitam a oferta de novas unidades contribuindo para que os preços de venda e do aluguel se fixem num patamar elevado. Com relação à escassez dos terrenos, uma sugestão é tentar conscientizar a sociedade de que o tombamento e a preservação de áreas urbanas tem também o efeito perverso de limitar a oferta de novas moradias. O mesmo acontece com medidas que impõem restrições sobre a construção, tais como a altura do empreendimento, o tipo de material, os critérios de sustentabilidade verde, etc. Cabe mencionar que mesmo nos Estados Unidos, pivô da crise econômica de 2008, o preço dos imóveis não se elevou de modo homogêneo por todo o território americano. A elevação se concentrou mais fortemente em áreas onde havia restrições sobre a construção.

\section{COMENTÁRIOS FINAIS}

Este estudo tem como objetivo analisar os determinantes da demanda por crédito imobiliário no Brasil assim como verificar o efeito que um choque restritivo de política monetária poderá ter sobre o setor imobiliário. Com base nos resultados obtidos, podemos extrair os seguintes resultados. Primeiro, os resultados parecem estar em concordância com outros estudos que mostram que as variáveis ligadas a preço como a taxa de financiamento e o preço dos imóveis são os fatores mais importantes para explicar a demanda por hipoteca. Segundo, observa-se ainda a ocorrência de causalidade reversa entre as concessões de crédito e preço dos imóveis no sentido de existir um processo de realimentação onde a demanda por crédito influencia também o preço do imóvel. Terceiro, com base no modelo de mudança de regime tipo Markov Switching, pode-se verificar que a demanda por crédito imobiliário tem estado sujeita a ciclos de retração e expansão desde 2003. Um regime ligado à fase recessiva sendo que os dois outros estão atrelados à fase expansiva do ciclo de crédito.

O ciclo de expansão que tem início ao final de 2005 é marcado pela alternância de dois regimes. 0 regime que se concentra do final de 2005 até o inicio de 2009 foi impulsionado por fatores pró-mercado decorrentes das mudanças na legislação, crescimento da economia, aumento da renda real, etc. A partir de 2009, a situação se altera, passando a prevalecer um regime onde a expansão do crédito é mais motivada por ações de medidas anticíclicas adotadas pelo governo federal com intuito de mitigar os efeitos da crise de 2007-2008. 
A fase recessiva do ciclo de crédito ligada a um único regime que se estende do início da amostra até 2005 retornando por volta de março de 2012 quando a série de concessões de crédito parece se desacelerar.

Num segundo estágio, aplicamos o modelo VAR estrutural com propósito de avaliar o efeito de um choque de política monetária sobre a demanda crédito imobiliário. De acordo com os resultados um choque contracionista de política monetária produz o efeito negativo sobre importantes todas as variáveis ligadas ao setor imobiliário. Assim, observa-se a queda acentuada e contínua da demanda por crédito imobiliário, do preço dos imóveis e do produto da construção civil assim como aumento da inadimplência. Isso pode ser um indício de que um aumento na taxa de juros pode provocar uma forte retração no mercado imobiliário no Brasil.

\section{BIBLIOGRAPHY}

Andrews, D. W. K. \& Moreira, M. J. (2006). Optimal two-sided invariant similar tests for instrumental variables regression. Econometrica, 74:715-52.

Andrews, D. W. K. \& Stock, J. H. (2005). Inference with weak instruments. Technical Working Paper 0313, NBER.

Araújo, V. L. (2012). Preferência pela liquidez dos bancos públicos no ciclo de expansão do crédito no Brasil: 2003-2010. Texto para Discussão 1717, IPEA.

Artle, R. \& Varaiya, P. (1978). Life cycle consumption and homeownership. Journal of Economic Theory, 18:38-58.

Assunção, J., Benmelech, E., \& Silva, F. (2012). Repossession and the democratization of credit. Working Paper 17858, NBER.

Baum, C. F., Schaeffer, M., \& Stillman, S. (2007). Enhanced routines for instrumental variables/GMM estimation and testing. Working Paper 667, Boston College Economics.

Bernanke, B. (1986). Alternative explanations of the money-income correlation. Carnegie-Rochester Conference Series on Public Policy, 25:49-100.

Bernanke, B. \& Gertler, M. (1995). Inside the black box: The credit channel of monetary policy transmission. Journal of Economic Perspectives, 9:27-48.

Bessler, D. A. \& Lee, S. (2002). Money and prices: U.S. data 1869-1914 (A study with directed graphs). Empirical Economics, 27:427-446.

Blanchard, O. \& Perotti, R. (2002). An empirical characterization of the dynamic effects of changes in government spending and taxes on output. Quarterly Journal of Economics, 117:1329-1368.

Blanchard, O. \& Watson, M. (1986). Are all business cycles alike? In Gordon, R., editor, The American Business Cycle: Continuity and Change, pages 123-156. NBER, University of Chicago Press, Chicago.

Bound, J., Jaeger, D. A., \& Baker, R. (1995). Problems with instrumental variables estimation when the correlation between instruments and endogenous variables is weak. Journal of the America Statistical Association, 90:443-450.

Brueckner, J. K. \& Follain, J. R. (1988). The rise and fall of ARM: An econometric analysis of mortgages choice. Review of Economic and Statistics, 70:93-102. 
Burnside, C. Eichenbaum, M. \& Fisher, J. D. M. (2003). Fiscal shocks and their consequences. Working Paper 9772, NBER.

Chib, S. (1996). Calculating posterior distributions and modal estimates in Markov mixture models. Journal of Econometrics, 75:79-98.

Christiano, L., Eichenbaum, M., \& Evans, C. (1999). Monetary policy shocks: What have learned and to what end? In Taylor, J. \& Woodford, M., editors, Handbook of Macroconomics, volume IA, pages 65-148. Elsevier.

Cook, S. (2004). Spurious rejection by cointegration tests incorporating structural change in the cointegrating relationship. Applied Economics Letters, 11:879-884.

Cragg, J. G. \& Donald, S. G. (1993). Testing identifiability and specification in instrumental variables models. Econometric Theory, 9:222-240.

Céspedes, B., Lima, E., \& Maka, A. (2008). Monetary policy, inflation and the level of economic activity in Brazil after the Real Plan: Stylized facts from SVAR models. Revista Brasileira de Economia, 62:123-160.

Davies, R. B. (1977). Hypothesis testing when a nuisance parameter is present only under the alternative. Biometrika, 64:247-54.

Demiralp, S. \& Hoover, K. (2003). Searching for the causal structure of a vector autoregression. Oxford Bulletin of Economics and Statistics, 65:745-767.

Dempster, A. P., Laird, N. M., \& Rubin, D. B. (1977). Maximum likelihood from incomplete data via the EM algorithm. Journal of Royal Statistical Society, 39:1-38.

Dhillon, U. S., Shilling, J. D., \& Sirmans, C. F. (1987). Choosing between fixed and adjustable-rate mortgages. Journal of Money Credit and Banking, 19:260-267.

Edelberg, W., Eichenbaum, M., \& Fisher, J. D. M. (1999). Understanding the effects of a shock to government purchases. Review of Economic Dynamics, 2:166-206.

Enders, W. (1995). Applied Econometric Time Series. John Wiley and Sons, New York.

Fackler, P. (1988). Vector autoregressive techniques for structural analysis. Revista de Analisis Econômico, 3:119-134.

Fatas, A. \& Mihov, I. (2001a). The effects of fiscal policy on consumption and employment: Theory and evidence. Mimeo, INSEAD.

Fatas, A. \& Mihov, I. (2001b). Fiscal policy and business cycles: An empirical investigation. Moneda y Credito, 211.

Favero, C. A. (2001). Applied Macroeconometrics. Oxford University Press.

FIPE (2011). Índice FIPEZAP de Preços de Imóveis Anunciados: Notas Metodológicas.

Gali, J., Lopez-Salido, J. D., \& Valles, J. (2004). Understanding the efects of government spending on consumption. International Finance Discussion Papers 2004-805, Federal Reserve Board.

Hamilton, J. (1989). A new approach to the economic analysis of nonstationary time series and the business cycle. Econometrica, 57:357-384.

Hamilton, J. (1991). A quasi-bayesian approach to estimating parameters for mixtures of normal distributions. Journal of Business and Economic Statistics, 9:27-39. 
Hamilton, J. (1993). Time Series Analysis. Princeton University Press, Princeton.

Hansen, B. E. (1992). The likelihood ratio test under nonstandard assumptions: Testing the Markov Switching Model of GDP. Journal of Applied Econometrics, 7:S61-S82. Erratum (1996) 11:195-8.

Jones, L., Miller, N. G., \& Riddiough, T. (1995). Residential mortgage choice: Does the supply side matter. Journal of Housing Economics, 4:71-90.

Judge, G. H., Griffiths, W. E., Lütkepohl, H., \& Lee, T. (1982). Introduction to the Theory and Practice of Econometrics. Wiley, New York.

Kahn, G. A. (1989). The changing interest sensitivity of the U. S. economy. Economic Review, Nov.:13-34.

Kim, C. (2004). Markov-switching models with endogenous explanatory variables. Journal of Econometrics, 122:127-136.

Kim, C. \& Nelson, C. (1999). State-Space Models with Regime Switching. MIT Press.

Kleibergen, F. \& Paap, R. (2006). Generalized reduced rank tests using the singular value decomposition. Journal of Econometrics, 127:97-126.

Koop, G. (2003). Bayesian Econometrics. Wiley.

Krolzig, H. (1997). M. Markov Switching Vector Autoregressions. Modelling, Statistical Inference and Application to Business Cycle Analysis. Springer-Verlag, Berlin.

Leibwitz, S. J. (2008). Anatomy of a train wreck: Causes of the mortgage meltdown. Independent policy report, The Independent Institute.

Leybourne, S. \& Newbold, P. (2003). Spurious rejections by cointegration tests induced by structural breaks. Applied Economics, 35:1117-1121.

Ma, A. (2002). GMM estimation and the new phillips curve. Economic Letters, 76:411-417.

Martins, B. S., Lundberg, E. L., \& Takeda, T. (2008). Crédito Habitacional no Brasil: Aperfeiçoamentos Institucionais e Avaliação da Evolução Recente. $\mathrm{BCB}$, Brasília. Relatório de Economia Bancária e Crédito.

McCarthy, J. \& Peach, R. W. (2002). Monetary policy transmission to residential investiment. Economic Policy Review, pages 139-158.

Miskin, F. S. (2007). Housing and monetary transmission mechanism. Working Paper 13518, NBER.

Moreira, M. J. (2003). A conditional likelihood test for structural models. Econometrica, 71:1027-48.

Murray, M. P. (2006). Avoiding invalid instruments and coping with weak instruments. Journal of Economic Perspectives, 20:111-132.

Noh, J. \& Kim, T. (2003). Behaviour of cointegration tests in the presence of structural breaks in variance. Applied Economics Letters, 10:999-1002.

Nothaft, F. E. \& Wang, G. H. (1991). Determinants of the ARM share of national and regional lending. Journal of Real State and Finance, 5:219-234.

Pesaran, M. H. \& Taylor, L. W. (1999). Diagnostic for IV regressions. Oxford Bulletin of Economics and Statistics, 61:255-281.

Pozdena, R. J. (1990). Do interest rates still affect housing? Economic Review, Summer:3-14. 
Rabanal, P. (2007). Does inflation increase after a monetary policy tightening? Answers based on an estimated DSGE model. Journal of Economic Dynamics and Control, 31:906-937.

Ramey, V. \& Shapiro, M. (1998). Costly capital reallocation and the effects of government spending. In Carnegie Rochester Conference on Public Policy.

Romer, D. H. \& Romer, C. (1994). What ends recessions? NBER Macroeconomics Annual, 9:13-57.

Rothenberg, T. J. (1971). Identification in parametric models. Econometrica, 39:577-59.

Ryding, J. (1990). Housing finance and the transmission of monetary policy. Quarterly Review, Summer. Federal Reserve Bank of New York.

Shea, J. (1997). Instrument relevance in multivariate linear models: A simple measure. Review of Economics \& Statistics, 79:348-352.

Sims, C. (1986). Are forecasting models usable for policy analysis? Federal Reserve Bank of Minneapolis Quarterly Review, Winter:1-16.

Sims, C. (1999). Drifts and breaks in monetary policy. Discussion paper, Princeton University.

Sims, C. (2001). Stability and instability in US monetary policy behavior. Discussion paper, Princeton University.

Sims, C. (2005). Hidden Markov chain models. Lecture notes, Princeton University.

Sims, C. A., Stock, J. H., \& Watson, M. W. (1990). Inference in linear time-series models with some unit roots. Econometrica, 58:113-144.

Spirtes, P., Glymour, C., \& Scheines, R. (1993). Causation, prediction, and search. Lecture Notes in Statistics, 81.

Spirtes, P., Glymour, C., \& Scheines, R. (2000). Causation, Prediction, and Search. MIT Press, 2nd edition.

Stock, J. H., Wright, J. H., \& Yogo, M. (2002). A survey of weak instruments and weak identification in generalized method of moments. Journal of Business and Economic Statistics, 20:518-29.

Stock, J. H. \& Yogo, M. (2005). Testing for weak instruments in linear IV regression. In identification and inference for econometric models. In Andrews, D. W. \& Stock, J. H., editors, Essays in Honor of Thomas Rothenberg, pages 80-108. Cambridge University Press.

Swanson, N. \& Granger, C. (1997). Impulse response functions based on a causal approach to residual orthogonalization in vector autoregressions. Journal of the American Statistical Association, 92:357-367.

Uhlig, H. (2005). What are the effects of monetary policy on output? Results from an agnostic identification procedure. Journal of Monetary Economics, 52:381-119.

Wooldridge, J. (2002). Econometric Analysis of Cross Section and Panel Data. MIT Press. 


\section{A. APÊNDICE A.}

PRIMOV

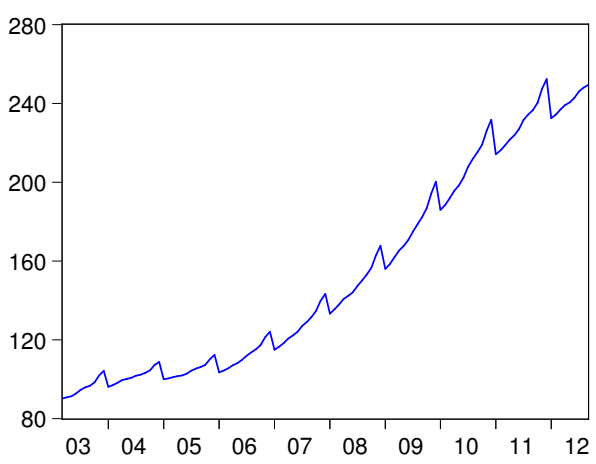

LRENDA

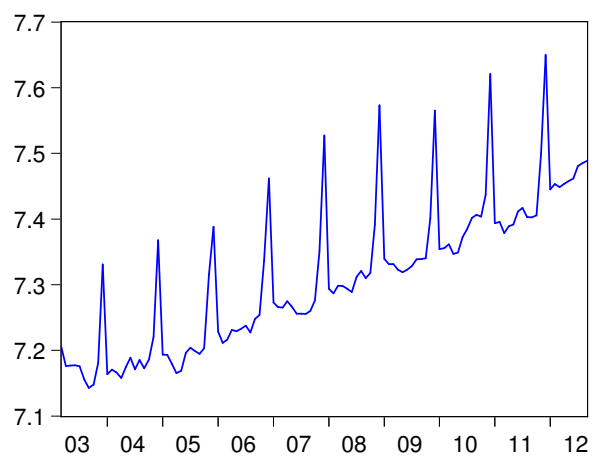

LALUG

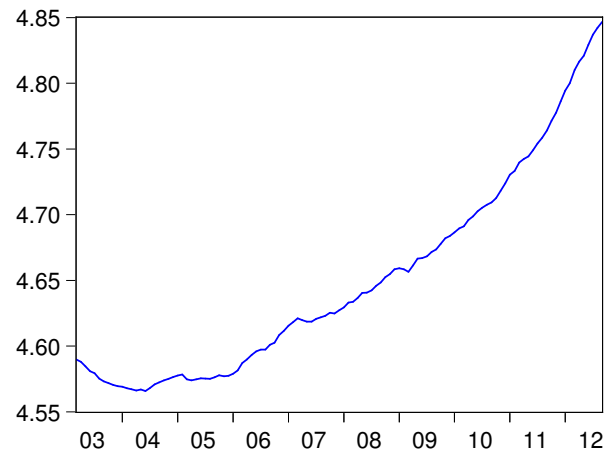

PRIMOV_SA

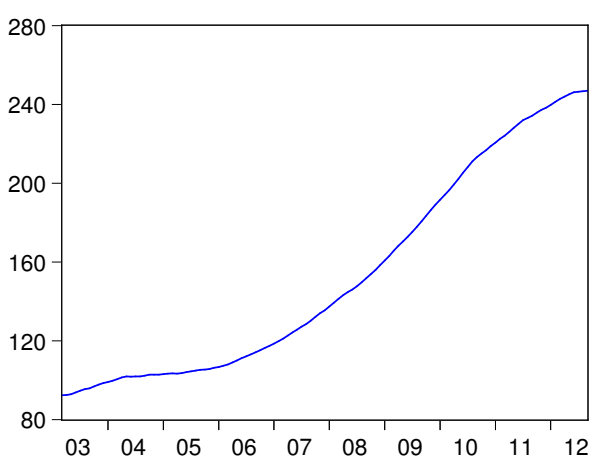

LRENDA_SA

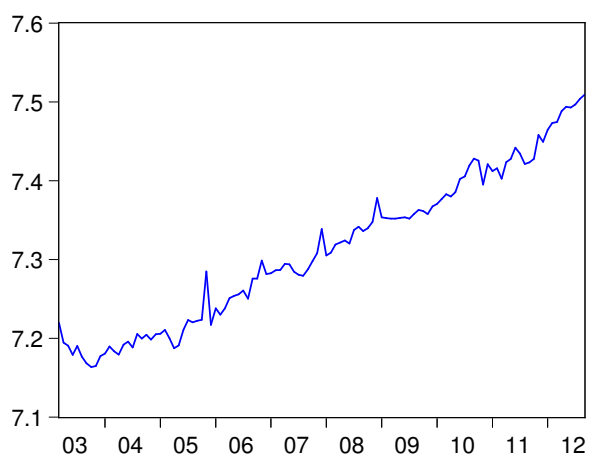

LPRIMOV SA

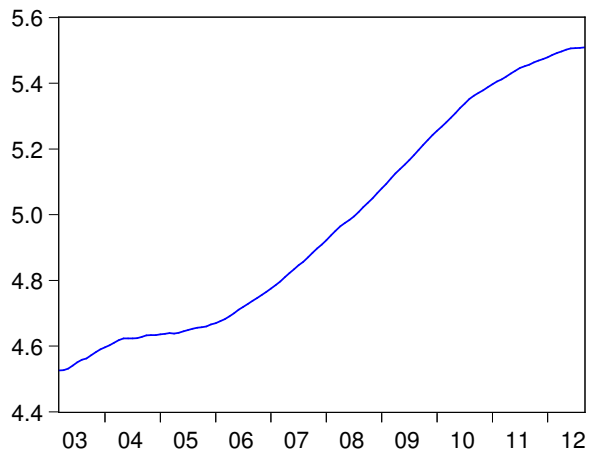




\section{B. APÊNDICE B. DESCRIÇÃO DAS VARIÁVEIS}

IPCA: Índice de Preços ao Consumidor Amplo - Fonte: Instituto Brasileiro de Geografia e Estatística (IBGE);

SELIC: Taxa de juros mensal nominal de curto prazo - Fonte: Banco Central do Brasil (BCB);

FIMOB: Concessões de financiamento para aquisição de imóveis residenciais novos e usados feitas no Sistema Financeiro de Habitação (SFH) - Fonte: BCB;

INAD: Inadimplência acima de três meses dos financiamentos imobiliários concedidos pelo SFH - Fontes: $\mathrm{BCB}$;

INDCC: Índice do produto industrial da construção civil - Fonte: IBGE;

DESP: Taxa de desemprego aberto de 30 dias (DESBR) do que é divulgada pela Pesquisa Mensal de Emprego (PME) - IBGE;

RENDA: Renda média do trabalho principal. Fonte: IBGE;

PRIMOV: Índice de Valores de Garantia de Imóveis Residenciais Financiados (IVG-R). Fonte: BCB;

ALUG: Índice do subitem aluguel dentro do item habitação do IPCA. Fonte: IBGE;

INCC: Índice Nacional do Custo da Construção - Geral. Fonte: Fundação Getúlio Vargas. 


\section{APÊNDICE C. GRÁFICO DAS VARIÁVEIS DO VAR}

FIMOBM3

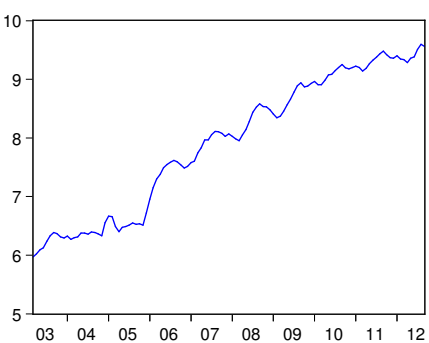

RENDA_SA

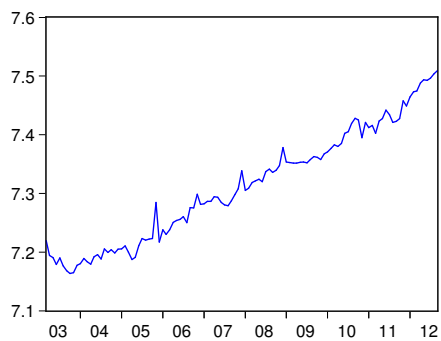

SELIC

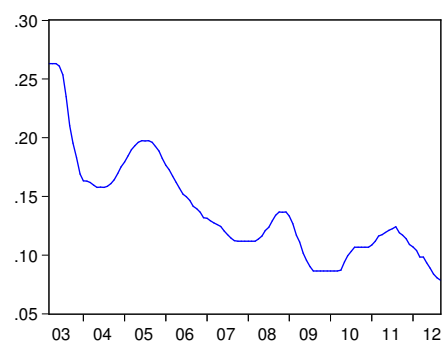

INDCCV

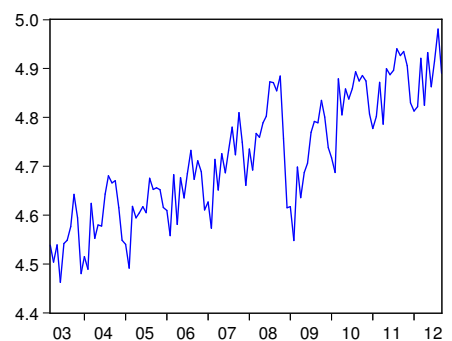

PRIMOV_SA

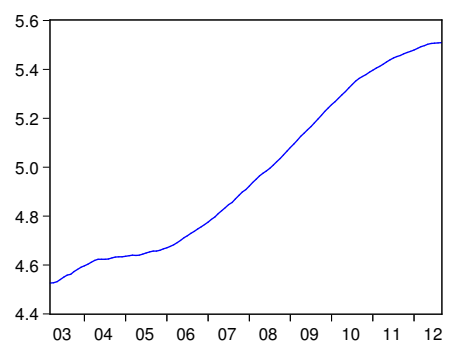

IPCA

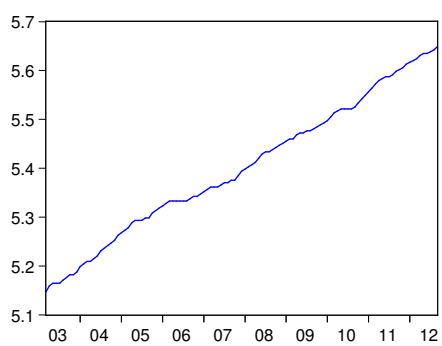

DESP_SA

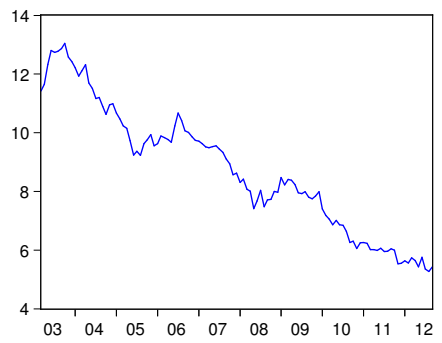




\section{APÊNDICE D. FUNÇÕES DE RESPOSTA IMPULSO}

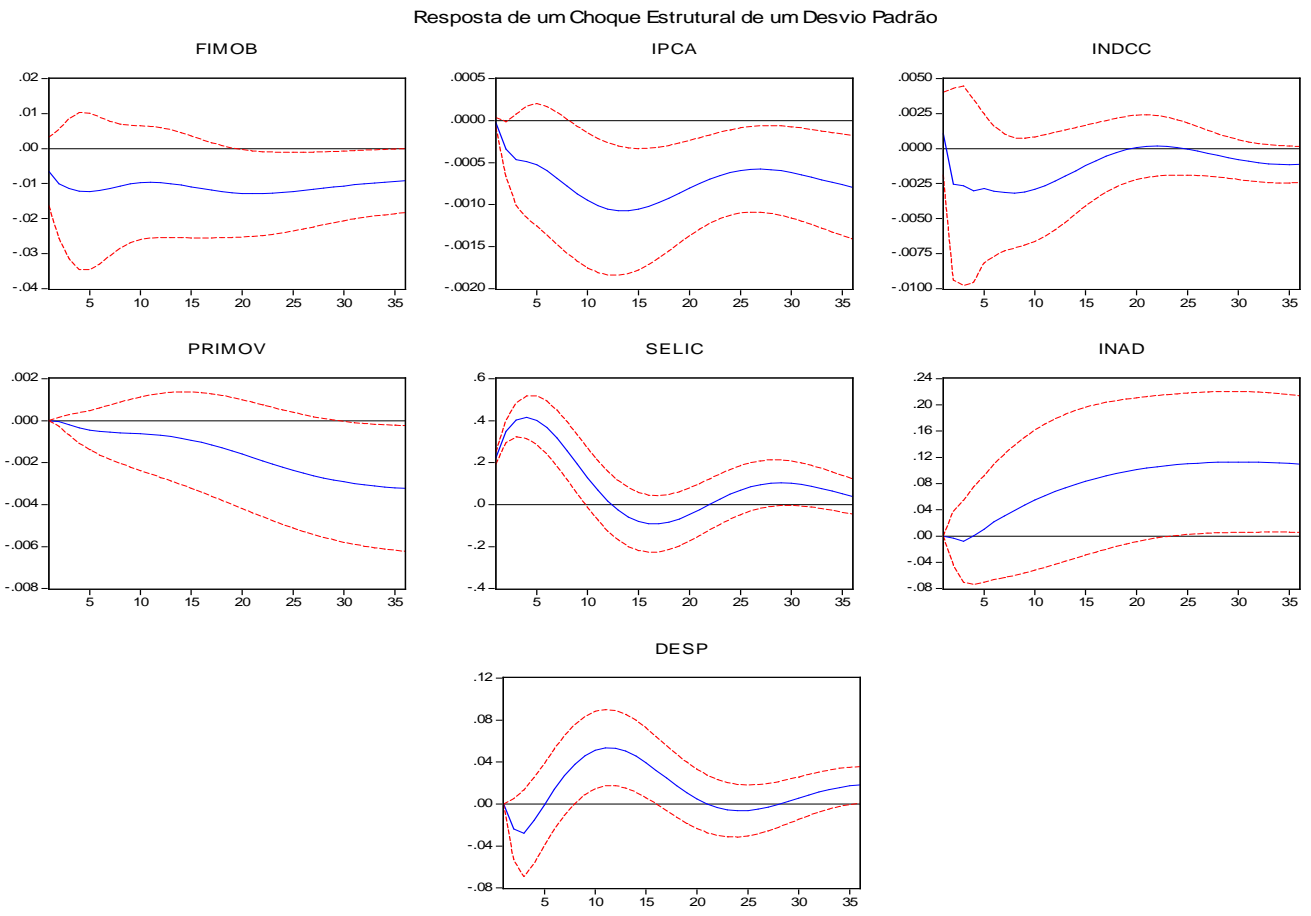


E. APÊNDICE E. CONCESSÕES DE CRÉDITO PARA VEÍCULOS NOVOS

CONVCMD

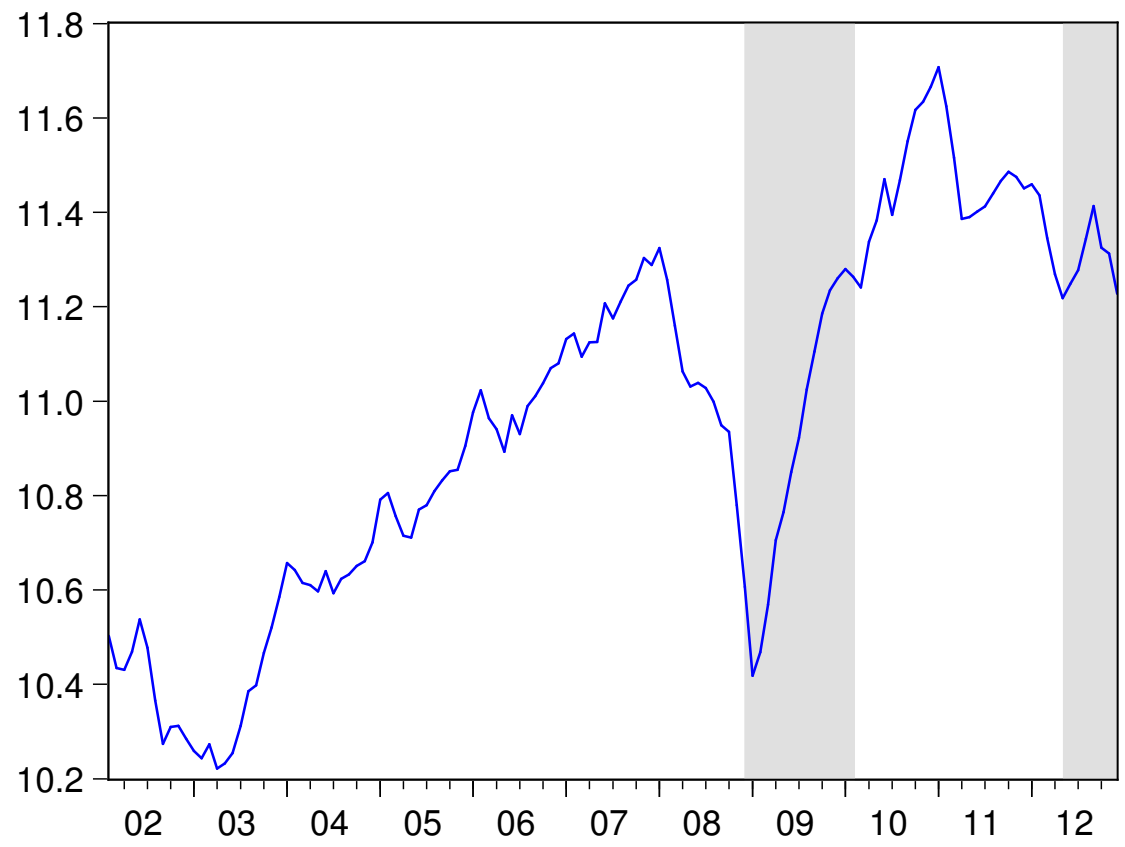




\section{F. APÊNDICE F. ENDIVIDAMENTO DAS FAMÍLIAS EM RELAÇÃO À RENDA ACUMULADA} EM 12 MESES

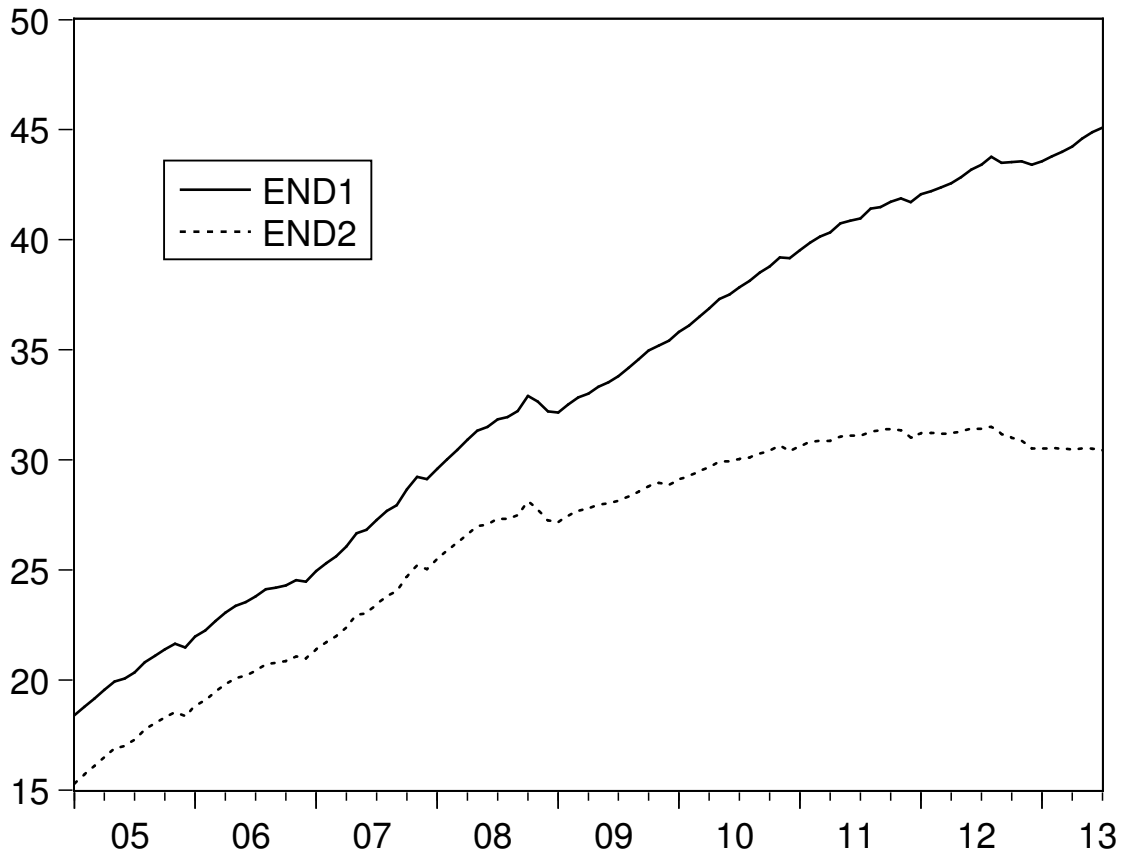

END1: Endividamento das famílias.

END2: Endividamento das famílias exceto crédito habitacional. 